\title{
BAD INVESTMENTS AND MISSED OPPORTUNITIES? POSTWAR CAPITAL FLOWS TO ASIA AND LATIN AMERICA
}

\author{
Lee E. Ohanian \\ Paulina Restrepo-Echavarria \\ Mark L. J. Wright \\ Working Paper 21744 \\ http://www.nber.org/papers/w21744 \\ NATIONAL BUREAU OF ECONOMIC RESEARCH \\ 1050 Massachusetts Avenue \\ Cambridge, MA 02138 \\ November 2015
}

The authors thank Patrick Kehoe as well as numerous seminar participants for helpful comments and Maria Alejandra Arias for outstanding research assistance. The views expressed in this paper are those of the authors and do not necessarily reflect the views of the Federal Reserve Banks of Chicago and St. Louis, the Federal Reserve System, or the National Bureau of Economic Research.

NBER working papers are circulated for discussion and comment purposes. They have not been peerreviewed or been subject to the review by the NBER Board of Directors that accompanies official NBER publications.

(C) 2015 by Lee E. Ohanian, Paulina Restrepo-Echavarria, and Mark L. J. Wright. All rights reserved. Short sections of text, not to exceed two paragraphs, may be quoted without explicit permission provided that full credit, including $(\mathcal{C}$ notice, is given to the source. 
Bad Investments and Missed Opportunities? Postwar Capital Flows to Asia and Latin America Lee E. Ohanian, Paulina Restrepo-Echavarria, and Mark L. J. Wright

NBER Working Paper No. 21744

November 2015

JEL No. F21,F32,F41,F44

\begin{abstract}
$\underline{\text { ABSTRACT }}$
Since 1950, the economies of East Asia grew rapidly but received little inter-national capital, while Latin America received considerable international capitaleven as their economies stagnated. The literature typically explains the failureof capital to flow to high growth regions as resulting from international capitalmarket imperfections. This paper proposes a broader thesis that country-specificdistortions, such as domestic labor and capital market distortions, also impactcapital flows. We develop a DSGE model of Asia, Latin America, and the Rest ofthe World that features an open-economy business cycle accounting framework tomeasure these domestic and international distortions, and to quantify their con-tributions to international capital flows. We find that domestic distortions havebeen the predominant drivers of international capital flows, and that the generalequilibrium effects of these distortions are very large. International capital market distortions also matter, but less.
\end{abstract}

Lee E. Ohanian

8283 Bunche Hall

UCLA, Department of Economics

Box 951477

Los Angeles, CA 90095

and NBER

ohanian@econ.ucla.edu

Paulina Restrepo-Echavarria

Federal Reserve Bank of St. Louis

1 Federal Reserve Bank Plaza,

St Louis, MO 63166

and Federal Reserve Bank of St Louis

paulinares@me.com
Mark L. J. Wright

Federal Reserve Bank of Chicago

230 South LaSalle St.

Chicago, IL 60604

and University of California, Los Angeles

and also NBER

mwright@frbchi.org 
Figure 1: Net Exports (\% GDP)

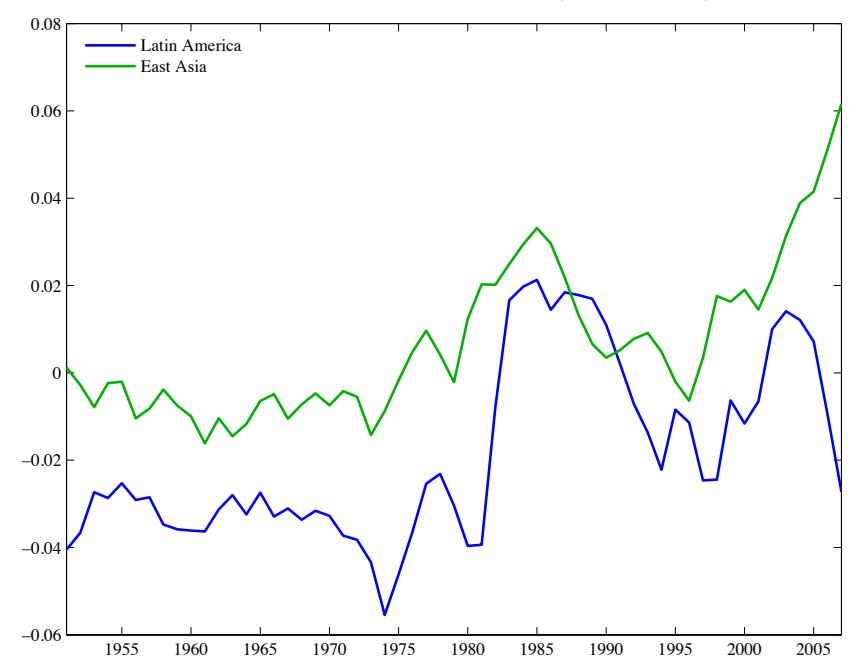

\section{Introduction}

Between 1950 and today, the economies of East Asia boomed while the economies of Latin America stagnated. At the same time, international capital flowed into Latin America in much greater quantities that it did into East Asia: as shown in Figure 1, netexports for East Asia (Japan, South Korea, Singapore, Hong Kong and Taiwan) were close to zero after the war, while the net exports of Latin America (Argentina, Brazil, Chile, Colombia, Mexico and some smaller economies) were consistently negative. This is surprising because, all else equal, rapidly growing countries should generate higher capital returns and thus should receive more capital than slow growing countries.

Why didn't international capital flow into East Asia in greater quantities, and flow out of Latin America? Many studies implicitly adopt the "all else equal" aspect of this argument and attempt to explain observed capital flow by focusing on imperfections in international capital markets that limit the opportunities to move capital out of slow growing regions and into fast growing regions. In contrast, in this paper, we question the validity of the "all else equal" assumption and argue that country-specific distortions, such as frictions and inefficiencies in domestic labor and capital markets, reduced the return to investment in East Asia, increased returns in Latin America, and thus altered the incentives to reallocate capital.

Our argument is quite simple, and is based on the impact of distortions in domestic capital and labor markets that either reduce the incentives and/or the opportunities for investment. Domestic capital market distortions, which can include capital taxes, 
regulations, and domestic capital market inefficiencies, may reduce the return to capital even though capital is scarce as measured by capital-output ratios. If these capital market distortions are not priced, they will not show up in observed factor returns. Instead, it is the lower shadow return to capital investment that is relevant for investing. In terms of labor markets, distortions such as labor taxes, labor market regulations, and trade unions, can reduce the equilibrium supply of labor, which in turn will depress the marginal product of capital for any given amount of capital.

To make our case, we first develop a simple example economy that can be solved analytically to show that the incentives to reallocate capital across countries are affected not only by capital scarcity but also by distortions to labor and capital markets. We also show that the impact of labor market distortions are operative only off of the steady state growth path. This is important because we will show that the Latin American and Asian countries spend considerable time off of their steady states, and because studies based on long-run averages will necessarily miss the impact of labor market distortions. We next turn to the problem of measuring distortions to domestic capital and labor markets, as well as to international capital markets, using data on factor accumulation and employment, output and capital flows. To do this, we develop a multi-country dynamic stochastic general equilibrium model of the world economy augmented with "wedges" that affect the incentives to invest, work and trade capital internationally. This can be viewed as an adaptation of the business cycle accounting framework of Cole and Ohanian (2002) and Chari et al (2007), both of which focus on a closed economy, to an open economy setting through the introduction of an international wedge, in which a country-specific tax is applied to the purchase of international contingent claims.

With wedges added, the model can exactly replicate the data on economic outcomes in the world economy, including world capital flows. We then estimate the parameters of the model on a novel dataset of economic outcomes and capital flows in Latin America, East Asia, and the rest of the world (ROW; primarily North America, Europe, and Australasia), and use the estimated model to measure the relevant wedges. We find that the resulting wedges are occasionally large and vary substantially over time- domestic labor distortions change by as much as 50 percent over this period in all three regionsand show that movements in these wedges correspond closely to to significant policy changes and events that affect domestic and international factor markets. This allows us to argue that experiments on the wedges can be interpreted as policy experiments in the model. 
We then assess the importance of different wedges through a series of experiments in which we shut down a particular wedge, which we think of as corresponding to a particular policy intervention, in order to quantify the impact of frictions in domestic labor and capital markets, relative to frictions in international capital markets, on both international capital flows and domestic economic performance.

Our most striking finding is that domestic labor market distortions have played a substantial role in accounting for international capital flows. Domestic labor market distortions explain as much as 16 percent of Asian capital flows and as much as 40 percent of Latin American capital flows during the 1950s and 1960s. Domestic capital market distortions are only about half as important as domestic labor market distortions during the 1950s and 1960s for both Asia and Latin America, but are at least as important as international capital market distortions during the 1950s for Asia and much more important than international capital market distortions for Latin America during the 1950s.

We also find significant movements in our measure of international capital market distortions. This varies by as much as 10 percentage points over time within a region, which has affected Asian capital flows by as much as 30 percent during the past two decades. Contrary to what has been thought, after 1960 international capital market distortions encouraged borrowing in Asia by as much as $20 \%$ of GDP. At first glance it may be surprising that we find the impact of international capital market distortions to be large in recent times, given that many countries have liberalized their international capital markets over time. However, this finding simply reflects the legacy of the accumulation of international capital market distortions over time. Thus, even if international capital market imperfections are entirely removed, the history of international distortions affects economic activity long after those distortions are eliminated.

Lastly, we find large general equilibrium effects with changes in distortions in one country often having large effects on economic outcomes in other countries. Most notably, the capital and labor wedge in the rest of the world had significant, although partially offsetting, effects on capital flows into Asia. In net terms, the effect of rest of the world wedges was to reduce capital flows into Asia by more than $10 \%$ of GDP.

In summary, our results show that the surprising historical pattern of world capital flows is not primarily the result of imperfect international capital markets. Rather, it reflects domestic factors that would have limited capital flows to capital scarce countries even if international financial markets worked perfectly. 
The remainder of the paper is organized as follows. Section 2 discusses previous literature. Section 3 illustrates our arguments using a simple model that can solved analytically. Section 4 presents the model economy and describes how the closed economy wedge methodology is adapted to the open economy setting. Section 5 describes the methodology. Section 6 shows the implied wedges and the counterfactual results, and section 7 concludes.

\section{Previous Literature}

Our paper connects to four distinct but related literatures. We describe this below, and we also describe how our analysis differs considerably from all four approaches.

First, the paper contributes to the large literature testing the efficiency of international financial markets. Much of this literature proposes tests of the efficiency of capital flows by assuming the existence of a particular source of gains from inter-temporal trade and proceeding under the assumption that "all else is equal". For example, the best known test of the efficiency of international capital flows is due to Feldstein and Horioka (1980) and examines the correlation between domestic savings and domestic investment, noting that if capital flows are zero the two must be equal (this approach has also been adopted by Bayoumi and Rose (1993), Dooley, Frankel and Mathieson (1987), Frankel (1992), Sinn (1992), Taylor (1996), and Tesar (1991)). While this tautologically indicates whether capital flows are positive, this is not a sure indicator of the presence of international capital market inefficiencies as it may simply indicate that the gains from international trade in capital are small (other counterexamples have been proposed by Obstfeld (1986), among others). Similarly, Lucas (1990) assumed that poor countries are "capital scarce"and thus have high rates of return to capital, and then showed counterfactually that capital flows from poor countries to rich countries, while Gourinchas and Jeanne (2013) looked at fast growing countries and showed that capital also flowed away from them. As a consequence of these assumptions about the existence and source of gains from trade, these tests typically have low power against plausible alternatives. Our approach complements this literature on international financial market inefficiency by evaluating these imperfections using a very different framework. Specifically, our approach completely accounts for observed capital flows through a range of forces. Our approach thus adds the important dimension of domestic factors, as well as international factors, to understanding capital flows, and is thus robust to some auxiliary 
assumptions about the sources of gains from trade, and allows testing of others.

Second, the paper is related to the literature that estimates the marginal product of capital in different countries, and uses those estimates to draw inferences about international capital market inefficiencies. Caselli and Feyrer (2007) estimates the marginal product of capital for many countries and find that they have converged over time, once the marginal products are adjusted for the share of non-reproducible capital, such as land and natural resources. They conclude on the basis of this convergence that international capital market distortions have become less important over time. ${ }^{1}$

Third, our paper also contributes to a small literature on business cycle accounting in open economies. Whereas Lama (2011) and Rahmati and Rothert (2011) adopt a partial equilibrium (small open economy) approach, place strong restrictions on the form of international capital trade, and apply it to individual emerging market economies, we show how to apply a general equilibrium complete markets model to data on the world economy constituted from multiple countries.

Our paper is also related to Gourinchas and Jeanne (2013). They conduct a steady state analysis of capital flows in a deterministic open economy growth model augmented with wedges on investment and savings (analogous to our international wedge), to study time-averaged data from 1980 to 2000 for individual countries. They find that the international wedge (their savings wedge) is the main reason why capital flowed out of the fast growing economies of East Asia.

Our approach complements theirs by focusing on the dynamics of capital flows in a stochastic model, rather than long-run capital flows in a deterministic model. Moreover, our dataset covers a longer period, from 1950-2007. Our finding of the pre-eminent role of domestic factor market distortions, especially labor market distortions, is partially due to the longer time period that we study (we find that East Asian factor markets are especially distorted in the 1950s and 1960s) but is largely due to the transitional dynamics, which are absent from Gourinchas and Jeanne. As described in Section 3, we show that the labor wedge only affects capital flows out of steady state, which means that this force cannot be identified in the steady state analysis of Gourinchas.

Last, our paper also contributes to the literature on East Asian growth and the debate as to the relative contribution of rapid factor accumulation (Young 1995) and productivity

\footnotetext{
${ }^{1}$ Monge-Naranjo et al (2015) extend the Caselli and Feyrer (2007) approach and propose a method to better estimate output shares of natural resources to adjust the estimated marginal products of physical and human capital.
} 
growth (Hsieh 1999) in explaining this growth. We argue that incorporating data on international capital flows, and understanding the causes of the observed rapid factor accumulation, help to shed light on this debate. Specifically, we find evidence for substantial distortions in East Asian factor markets, particularly labor markets, in the 1950s that both depressed returns to investment and thus limited the incentive for international capital inflows and, as the distortions were unwound throughout the rest of the Century, were an important force driving the observed rapid factor accumulation.

\section{Domestic Distortions and Capital Flows: An Ex- ample}

To understand how domestic capital and labor market distortions affect international capital flows, and their relation to the marginal product of capital, consider an economy that looks like the simple one-sector neoclassical growth model in which households have preferences over consumption $c$ and hours worked $h$ and face constant taxes $\tau^{k}$ on capital income and $\tau^{h}$ on labor earnings. For simplicity we assume that production is Cobb-Douglas with output elasticity $\alpha$ and normalize productivity to one. We consider domestic capital and labor market distortions in turn.

\subsection{Domestic capital market distortions}

First, to focus attention on the capital wedge, assume labor is exogenously supplied and normalize the amount to one. If the country is in steady state, the inter-temporal first order condition yields:

$$
1=\beta\left(\left(1-\tau^{k}\right) \alpha k^{\alpha-1}+1-\delta\right)
$$

where $k$ is the level of capital (and therefore also the capital to labor ratio), and $\delta$ is the depreciation rate. That is, the after-tax return to capital is pinned down by the discount factor of the country $\beta$. Now suppose we open up this economy to trade in capital with the rest of the world at some gross interest rate $R$. Whether or not capital flows into or out of this economy depends on a comparison between the after tax rate of return on capital in the country, in steady state given by $1 / \beta$, and the world interest rate $R$. Note that this is independent on the marginal product of capital in the country; 
if the marginal product is high in steady state it is because there is an offsetting high tax on capital income.

The effect of domestic capital market distortions impacts the relationship between capital flows and the marginal product of capital both in the steady state, as shown here, and also out of steady state, as we will show below.

\subsection{Domestic labor market distortions}

Second, to understand the role played by the labor wedge in determining capital flows, now consider an economy where labor is supplied endogenously. If the economy begins in steady state, the analysis is unchanged. Although the labor wedge may result in less labor being supplied, the capital stock adjusts in steady state so that the rate of return to capital, and the capital to labor ratio, are the same as in the model with exogenous labor supply. That is, in steady state, the labor wedge has no impact on capital flows. Instead, assume that the economy begins with little capital and is on the transition path to steady state. We will later show that off steady state dynamics are empirically very relevant for both Asia and Latin America over the period we study. The same comparison between marginal products and world interest rates above determine the direction and size of capital flows. But now, for a given capital stock, a high labor wedge means a lower supply of labor and a lower marginal product of capital. In general, when the economy is opened up to capital flows, the supply of labor will adjust as a result of a wealth effect. For simplicity, it is therefore convenient to assume GHH preferences (Greenwood, Hercovitz and Huffman 1988) where the wealth effect on labor supply is absent

$$
u(c, h)=\ln \left(c-\frac{\varphi}{1+\gamma} h^{1+\gamma}\right)
$$

It is then easy to verify that the marginal product of capital in this economy is given by

$$
M P_{k}=\alpha\left(\frac{k}{h}\right)^{-(1-\alpha)}=\alpha\left(\frac{1-\alpha}{\varphi}\left(1-\tau_{h}\right) k^{\alpha}\right)^{(1-\alpha) /(\gamma+\alpha)},
$$

which is decreasing in the labor wedge. That is, for a given level of capital, the marginal product of capital is lower the higher is the labor wedge and hence the less likely is capital to flow into an otherwise capital poor country. 


\subsection{Combining capital and labor market distortions}

To make this point more generally, consider a large group of countries that differ in the extent of the distortions faced by their domestic labor and capital markets. Imagine that the endowment of capital of each country is varied so that each has exactly the same level of per capita output. That is, some countries have very high distortions and need a high endowment of capital to produce a given output per capita level, while others have very low distortions and need less capital to obtain the same per capita output level. Now open each of these countries up to international trade in capital.

The resulting capital flows are depicted in Figure 2 for a group of countries with output one-third the level of an undistorted economy (as in the comparison of Latin America to the USA). Each point in the diagram is a country, with the $\mathrm{x}$-axis measuring the size of the capital market distortion and the y-axis measuring the size of the labor market distortion. The lines in the picture represent equal levels of capital flows measured as the ratio of net exports to output (as output is the same in each country by construction, the same pattern applies to the level of exports). Each line slopes down, reflecting the fact that each distortion substitutes for the other in affecting capital flows, even though they work in different ways. As we move upwards increasing the labor wedge for a given capital wedge, the supply of labor for a given level of capital falls reducing both output and the marginal product of capital. To keep output per capita constant, the capital stock must be increased further depressing the return to capital. To keep capital flows constant, the capital wedge must fall.

As shown in the figure, for a bunch of countries with identical initial levels of output per capita, whether or not openness to trade in capital leads to inflows or outflows, as well as the determinants of the size of those outflows, depends on why their output is low. If a country is undistorted, it must have little capital, a high return to capital, and hence capital flows in. If a country is heavily distorted, it must have more capital to attain the same level of output, and hence low returns so that openness leads to capital outflows. Moreover, for typical parameterization of the elasticity of labor supply (for example, Neumeyer and Perri (2005)), as shown in the picture, the vertical distance between these iso-capital flow lines is small indicating that small changes in the labor wedge have much larger effects on capital flows than do changes in the capital wedge.

In the remainder of the paper, we use a more general version of the model allowing for varying stochastic wedges and non-GHH preferences to assess the relative impact of domestic an international distortions in determining capital flows to Asia and Latin 
Figure 2: Effect of domestic wedges on capital flows

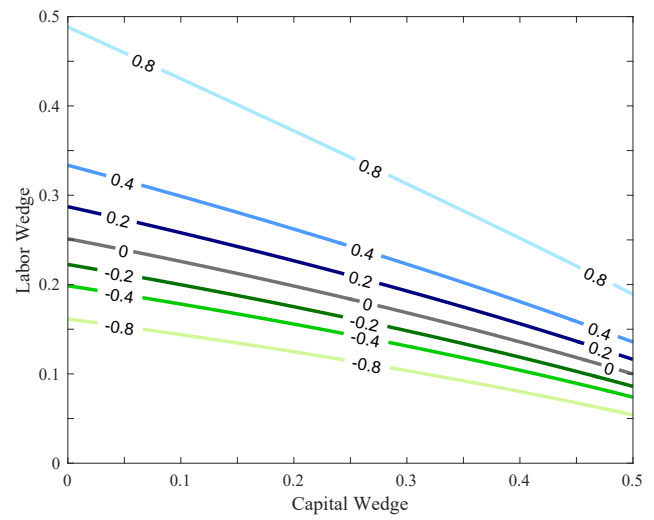

America.

\section{An Open Economy Business Cycle Accounting Frame- work}

We first summarize a quantitative framework that we will use to measure changes in domestic and international factor market distortions and to quantify their impact on macroeconomic activity over time. The framework extends the closed-economy business cycle accounting approach of Cole and Ohanian (2002) and Chari, Kehoe, and McGrattan (2007) to a general equilibrium open economy accounting framework, so that we can completely account for international capital flows, as well as consumption, investment, labor, and output.

\subsection{Households}

Consider a world populated by $j$ countries with $j=R, L, A$, where $R$ stands for the "Rest of the World," $L$ stands for "Latin America," and A stands for "Asia". Each country has $N_{j t}$ population at time $t=0,1, \ldots$. The decisions of each country are made by a representative agent with preferences over consumption and leisure ordered by

$$
E_{0}\left[\sum_{t=0}^{\infty} \beta^{t}\left\{\ln \left(\frac{C_{j t}}{N_{j t}}\right)-\frac{\psi}{1+\gamma} h_{j t}^{1+\gamma}\right\} N_{j t}\right] .
$$


While these preferences are quite standard, it is important to note that many of the results below can be established for more general preference orderings.

At $t=0$ each country $j$ chooses a state contingent stream of consumption levels $C_{j t}$, hours worked $h_{j t}$, purchases of capital to be rented out next period $K_{j t+1}$ and state contingent international bond holdings $B_{j t+1}$ subject to a sequence of flow budget constraints for each state and date

$$
\begin{aligned}
C_{j t}+P_{j t}^{K} K_{j t+1}+E_{t}\left[q_{t+1} B_{j t+1}\right] \leq & \left(1-\tau_{j t}^{h}\right) W_{j t} h_{j t} N_{j t}+\left(1-\tau_{j t}^{B}+\Psi_{j t}\right) B_{j t}+T_{j t} \\
& +\left(1-\tau_{j t}^{K}\right)\left(r_{j t}^{K}+P_{j t}^{* K}\right) K_{j t}+\Pi_{j t},
\end{aligned}
$$

with initial capital $K_{j 0}$ and bonds $B_{j 0}$ given. Here, $q_{t+1}$ is the (risk adjusted) price of a bond that pays off in a particular state in period $t+1, W_{j t}$ is the wage, $r_{j t}^{K}$ the rental rate of capital in country $j, P_{j t}^{K}$ is the price of new capital goods, and $P_{j t}^{* K}$ is the price of old capital goods.

The $\tau^{i}$ for $i=h, B, K$ represent taxes or "wedges" on wage income (labor wedge), international investment income (international wedge) and domestic capital services income (capital wedge) respectively. The $\Psi_{j t}$ terms are additional taxes on foreign investment income, taken as given by the country, that are introduced for technical reasons that we describe below. All revenue from these taxes above the government spending level $G_{j t}$ are rebated in lump sum fashion each period as $T_{j t}$. Households also receive profits $\Pi_{j t}$ from their ownership of domestic firms.

Note that the wedges on wage income and capital services income are standard in the business cycle accounting literature (see Cole and Ohanian (2002), and Chari, Kehoe, and McGrattan (2007), but the wedge on interest income from international bonds is added to to create an open economy accounting framework. This term drives a wedge between world inter-temporal prices and the returns received on foreign investments by individuals in a specific country. This wedge captures not only taxes on international financial transactions, but is a proxy for other capital market imperfections including capital controls, exchange controls, and other frictions that impede capital flows. The estimated stochastic process for this term will allow us to construct a time series measure of variation over time in international capital market efficiency by country that we will document, interpret within the context of institutional and regulatory changes at the regional level, and that we will use to assess to assess its impact on macroeconomic 
activity.

\subsection{Firms}

Each country has two representative firms. The first hires labor and capital to produce the consumption good using a standard Cobb-Douglas technology of the form $A_{j t} K_{j t}^{\alpha} h_{j t} N_{j t}^{1-\alpha}$. The second type of firm produces new capital goods $K_{j t+1}$ using $X_{j t}$ units of investment (deferred consumption) and $K_{j t}$ units of the old capital good. Their objective function is $P_{j t}^{K} K_{j t+1}-X_{j t}-P_{j t}^{* K} K_{j t}$, and they face a capital accumulation equation with convex adjustment costs $\phi$ of the form:

$$
K_{j t+1}=(1-\delta) K_{j t}+X_{j t}-\phi\left(\frac{X_{j t}}{K_{j t}}\right) K_{j t}
$$

\subsection{Growth, Shocks and an Intensive Form Problem}

The world economy has grown substantially over the period under study. In order to capture this growth, while preserving a non-degenerate long run distribution of economic activity across countries, we designate the rest of the world $j=R$ as a reference country with the other countries' population and productivity evolving relative to this reference level. Specifically, for $j=R$ we assume that productivity and population evolve according to

$$
\begin{aligned}
& \ln A_{R t+1}=\ln A_{R t}+\ln \pi_{s s}+\sigma_{R}^{A} \varepsilon_{R t}^{A}, \\
& \ln N_{R t+1}=\ln N_{R t}+\ln \eta_{s s}+\sigma_{R}^{N} \varepsilon_{R t}^{N},
\end{aligned}
$$

while for the other countries, we have $A_{j t}=a_{j t} A_{R t}$, and $N_{j t}=n_{j t} N_{R t}$. The levels of government spending and the labor, capital and international wedges in all countries follow first order autoregressive processes.

Given that the world economy grow stochastically, it is convenient to define a stationary intensive form version of the model. Let $a_{R t}=n_{R t}=1$, and define $Z_{t}=A_{R t}^{1 /(1-\alpha)} N_{R t}$ as the level of effective labor in the rest of the world, with $z_{t+1}=Z_{t+1} / Z_{t}$ its growth rate. Also define the growth rates of rest of the world productivity and population as $\pi_{t+1}=A_{R t+1} / A_{R t}$ and $\eta_{t+1}=N_{R t+1} / N_{R t}$ respectively, so that $z_{t+1}=\pi_{t+1}^{1 /(1-\alpha)} \eta_{t+1}$. Dividing real variables by $Z_{t-1}$ and denoting the result with lower case letters, this allows us to write down an intensive form version of the economy in which households 
maximize

$$
E_{0}\left[\sum_{t=0}^{\infty} \beta^{t}\left(\prod_{s=0}^{t} \eta_{s}\right)\left\{\ln \left(c_{j t}\right)-\frac{\psi}{1+\gamma} h_{j t}^{1+\gamma}\right\} n_{j t}\right]
$$

subject to

$$
\begin{aligned}
c_{j t}+P_{j t}^{K} z_{t} k_{j t+1}+z_{t} E_{t}\left[q_{t+1} b_{j t+1}\right] \leq & \left(1-\tau_{j t}^{h}\right) \frac{W_{j t} h_{j t} N_{j t}}{A_{R t-1}^{1 /(1-\alpha)} N_{R t-1}}+\left(1-\tau_{j t}^{B}+\Psi_{j t}\right) b_{j t}+t_{j t} \\
& +\left(1-\tau_{j t}^{K}\right)\left(r_{j t}^{K}+P_{j t}^{* K}\right) k_{j t}+\frac{\Pi_{t}}{z_{t-1}} .
\end{aligned}
$$

The household's first order conditions are given by

$$
\begin{aligned}
\psi h_{j t}^{\gamma} & =\frac{1}{c_{j t}}\left(1-\tau_{j t}^{h}\right) w_{j t} n_{j t} \eta_{t}, \\
1 & =E_{t}\left[\beta \eta_{t+1} \frac{n_{t+1 j}}{n_{t j}} \frac{c_{j t}}{c_{j t+1}}\left(1-\tau_{j t+1}^{K}\right) \frac{r_{j t+1}^{K}+P_{j t+1}^{* K}}{P_{j t}^{K} z_{t}}\right], \\
\frac{c_{j t+1}}{c_{j t}} & =\beta \eta_{t+1} \frac{n_{j t+1}}{n_{j t}}\left[\left(1-\tau_{j t+1}^{B}+\Psi_{j t+1}\right) \frac{1}{q_{t+1} z_{t}}\right] .
\end{aligned}
$$

It is straightforward to construct similar intensive form problems for the firms in this economy. Then, the first order optimality conditions of the consumption good firm are given by

$$
w_{j t}=(1-\alpha) a_{j t} \pi_{t}\left(\frac{k_{t j}}{h_{t j} n_{j t} \eta_{t}}\right)^{\alpha}, \text { and } r_{j t}^{K}=\alpha a_{j t} \pi_{t}\left(\frac{k_{j t}}{h_{j t} n_{j t} \eta_{t}}\right)^{-(1-\alpha)},
$$

while for the investment good producing firm they are

$$
P_{j t}^{K}=\frac{1}{1-\phi^{\prime}\left(\frac{x_{j t}}{k_{j t}}\right)} \text {, and } P_{j t}^{* K}=P_{j t}^{K}\left(1-\delta-\phi\left(\frac{x_{j t}}{k_{j t}}\right)+\phi^{\prime}\left(\frac{x_{j t}}{k_{j t}}\right) \frac{x_{j t}}{k_{j t}}\right) \text {. }
$$

\subsection{Technical Issues}

In solving for the equilibrium of this economy, four technical issues arise. First, as a natural benchmark, we have assumed that the world economy has complete markets. Given our continuous state space, this means that each country has an infinite dimensional portfolio decision to make each period. To surmount this problem, we establish that the solution to a particular pseudo-social planners problem corresponds to 
the equilibrium of our complete markets economy. Appendix A describes in detail the mapping between the competitive equilibrium problem and the pseudo-social planners problem.

The second and third issues relate to the fact that there are a large number of state variables in the model. Specifically, for each country there are 6 exogenous and 2 endogenous state variables. For $J=3$, after one normalization, we have 23 state variables of which 6 are endogenous. The second issue is that we must economize on the interactions between wedges as there are 272 (that is, $17^{*} 16$ ) terms in the covariance matrix which would need to be estimated on less than 60 years of data. As a consequence, above we have imposed no interaction between these wedges and will show below in Section 5 that for our purposes this is an empirically reasonable assumption. Third, in order to solve a model with a large number of state variables, we must use perturbation methods. This requires choosing an appropriate point to take perturbations around, and leads to our fourth technical issue: without further assumptions, the model does not in general possess a non-degenerate steady state in consumption levels. To see this, note that for our reference country $R$ and any other country $j$ we can take equation (3) above and rearrange to obtain

$$
\frac{c_{j t+1} / n_{j t+1}}{c_{R t+1}}=\frac{c_{j t} / n_{j t}}{c_{R t}} \frac{1-\tau_{j t+1}^{B}+\Psi_{j t}}{1-\tau_{R t+1}^{B}+\Psi_{R t}} .
$$

This means we cannot separately identify each country's international wedge $\tau_{j}^{B}$ and additional tax on foreign investment income $\Psi_{j}$. In what follows we normalize these levels for our reference country to zero. This means that for all $j \neq R$ we can define consumption relative to the rest of the world as $\theta_{j t}=\left(c_{j t} / n_{j t}\right) / c_{R t}$, from which $\theta_{j t+1}=\theta_{j t}\left(1-\tau_{j t+1}^{B}+\Psi_{j t+1}\right)$. Inspection of this equation reveals that, unless the steady state values of $\tau_{j t+1}^{B}$ and $\Psi_{j t+1}$ are zero, relative consumption levels will diverge; hence we impose this on the model. This ensures that the deterministic version of the model possesses non-degenerate steady state relative consumption levels, but does not guarantee that it is unique; in general, the relative levels will depend on the exact path of international wedges faced over time. To rule this out, we impose the assumption that, in equilibrium, the additional tax on international investment income $\Psi_{j t}$ satisfies

$$
\Psi_{j t}=\left(1-\tau_{j t+1}^{B}\right)\left[\left(\frac{\theta_{j t}}{\psi_{j 0}}\right)^{-\psi_{j 1}}-1\right]
$$


Analogs of this assumption are commonly made in small open economy models in order

to ensure existence of a steady state in consumption (see Schmitt-Grohe and Uribe (2003) for a discussion of alternative approaches).

Under this assumption, relative consumption levels evolve according to

$$
\ln \theta_{j t+1}=\psi_{j 1} \ln \psi_{j 0}+\left(1-\psi_{j 1}\right) \ln \theta_{j t}+\ln \left(1-\tau_{j t+1}^{B}\right)
$$

so that the steady state consumption ratio weighted by population is then $\psi_{j 0}$. Note that as the wedge is in general not iid, we have autoregressive innovations:

$$
\ln \left(1-\tau_{j t+1}^{B}\right)=\mu_{j}^{\tau^{B}} \ln \left(1-\tau_{j t}^{B}\right)+\sigma_{j}^{\tau^{B}} \varepsilon_{j t}^{\tau^{B}}
$$

\subsection{Remarks on Open Economy Business Cycle Accounting}

It is important to point out that, aside from the technical details underlying the method, the basic approach is intuitive and (somewhat) robust to alternative assumptions. Identification of the wedges is quite intuitive. The international wedge, for example, is determined by differences in consumption growth rates across countries from equation (3). Likewise, the capital wedge is identified by differences in estimated marginal products of capital (from capital/output ratios) from growth rates of consumption within a country (2), and the labor wedge is determined from a comparison of hours worked and consumption levels within a country (1).

Up to some concerns about functional forms and parameter values, which we return to in a moment, these comparisons take a relatively modest stand as to the source of gains from international inter-temporal trade, and the barriers to achieving these gains. Indeed, our framework nests a number of common models. To see this, consider the example of a limited commitment model of international financial frictions along the lines of Kehoe and Perri (2002). In this model, regardless of whether or not capital flows are motivated by consumption smoothing, capital scarcity or a desire to shift consumption through time (that is, tilt the consumption profile), the model predicts that the international wedge should never be positive when net exports are negative. Intuitively, this is because the limited commitment constraint does not bind when the country receives a positive net resource transfer. Likewise, a defaultable debt model along the lines of Eaton and Gersovitz (1981) predicts that the international wedge should be zero whenever the country is a net saver (that is, have positive net financial 
assets) regardless of whether or not the country is motivated to save to insure future consumption fluctuations, or to take advantage of profitable overseas investments.

This is not to say that the approach is free of restrictions imposed by functional forms and parameter values. However, we argue that these concerns are small relative to the alternatives. On the question of functional forms, the long run balanced growth observed for many economies places relatively strong restrictions on the sets of functional forms for production and utility that are admissible. Essentially, at least asymptotically, both have to be invariant to scale suggesting that preferences need to be asymptotically iso-elastic (that is, have constant inter-temporal elasticities of substitution asymptotically) and that production functions need to have constant returns to scale. In addition, under relatively minor restrictions on the behavior of the marginal product of capital (essentially, analogs of the Inada conditions) it can be shown that all "neoclassical" production functions are asymptotically Cobb-Douglas (see Barelli and de Abreu Pessoa (2003) and Litina and Palivos (2008)). In any case, the robustness of our functional form assumptions can be assessed by replicating the above analysis under different assumptions. Likewise, robustness to alternative parameter values can be assessed.

In summary, while we do not claim that our approach is free from auxiliary assumptions, we argue that it is exposed to fewer auxiliary assumptions about the sources of gains from trade, and that assumptions about functional forms and parameter values can be assessed using conventional econometric and economic methods. Indeed, our approach is agnostic about the sources of gains from intertemporal trade, instead identifying them from the data.

In the next section we describe the application of this framework to post-war Asian and Latin American capital flows.

\section{$5 \quad$ Methodology}

Our approach extends the business cycle accounting methodology to an open economy framework, in which we can fully account for international capital flows, as well as consumption, investment, output, and labor input in all three regions.

We use data for each of the three regions together with the optimality conditions and measurement equations of the model to pin down the wedges. We use data on output, consumption, investment, hours worked, population for the rest of the world, Latin America and Asia, and net-exports for Latin America and Asia to compute seventeen 
wedges. If we feed the wedges back into our model we recover the original data.

We use a maximum likelihood estimation procedure and apply the Kalman filter to a linearized version of the model to compute the values of the wedges. We then use Bayesian estimation to simultaneously recover the processes for the wedges and some of the parameters of the model.

\subsection{Data and Processes for the wedges}

Our data for the Rest of the World is from OECD sources. We use the World Bank Global Development Indicators for Asia and Latin America, and we supplement using Mitchell (2001) and other country specific sources where necessary (see Appendix B for a full description of the dataset).

As discussed above, the data on real output, consumption, investment and population are non-stationary even with respect to a log-linear trend. Hence, consistent with the model we assume that long run growth is driven by random walks as proposed by Fernandez-Villaverde and Rubio-Ramirez (2007). In our context we assume this for two processes that are commonly thought to be extremely persistent: the efficiency wedge for the rest of the world $A_{R}$ and population for the rest of the world $N_{R}$. Thus, the growth rates of the efficiency wedge $(\pi)$ and population for the rest of the world $(\eta)$ are assumed to follow first-order autoregressive processes. We denote by $\pi_{s s}$ the mean growth rate of the efficiency wedge for the rest of the world and by $\eta_{s s}$ the mean growth rate of population.

As mentioned above, from the optimality conditions of the model we can see that all

variables grow at a factor $\left(\pi_{s s}\right)^{\frac{1}{1-\alpha}} \eta_{s s}$. Then, if we take the first differences of the efficiency wedge and population by defining $\pi_{t}=A_{R t} / A_{R t-1}=\pi_{s s} \exp \left(\sigma_{\pi} \varepsilon_{\pi_{t}}\right)$ and $\eta_{t}=N_{t} / N_{t-1}=\eta_{s s} \exp \left(\sigma_{N} \varepsilon_{N t}\right)$, we can derive an aggregate trend $Z_{t}=A_{R t}^{1 /(1-\alpha)} N_{R t}$, which is common to all the variables. Detrended variables are represented by lower case letters.

The process that we estimate for the international wedge is given by equations 4 and 5 in Section 4. We assume that the rest of the wedges follow first-order autoregressive processes around their steady-state values:

$$
\begin{aligned}
& \ln a_{j t+1}=\left(1-\rho_{j}^{a}\right) \ln a_{j s s}+\rho_{j}^{a} \ln a_{j t}+\sigma_{j}^{a} \varepsilon_{j t}^{a}, \\
& \ln n_{j t+1}=\left(1-\rho_{j}^{n}\right) \ln n_{j s s}+\rho_{j}^{n} \ln n_{j t}+\sigma_{j}^{n} \varepsilon_{j t}^{n},
\end{aligned}
$$




$$
\ln \tau_{j t+1}^{i}=\left(1-\rho_{j}^{\tau^{i}}\right) \ln \tau_{j s s}^{i}+\rho_{j}^{\tau^{i}} \ln \tau_{j t}^{i}+\sigma_{j}^{\tau^{i}} \varepsilon_{j t}^{\tau^{i}}
$$

and

$$
\ln g_{j t+1}=\left(1-\rho_{j}^{g}\right) \ln g_{j s s}+\rho_{j}^{g} \ln g_{j t}+\sigma_{j}^{g} \varepsilon_{j t}^{g},
$$

where $i=h, k, j=L, A$ for the productivity and population processes, and $j=R, L, A$ for the rest.

The process that we estimate for the international wedge is given by equations 4 and 5 in Section 4.

\subsection{Calibration and Estimation}

Our model includes utility and technology parameters, as well as the parameters that govern the stochastic processes for the wedges. We use standard values for parameters when they are available, and estimate the remaining parameters.

Specifically, we set the share of capital in the Cobb-Douglas production function $\alpha$ to 0.36 , the discount factor $\beta$ to 0.96 , and the depreciation rate $\delta$ to $7 \%$ per year. The elasticity of labor supply $\gamma$ is set to 1.5, which is standard. The other labor supply parameter $\psi$ cannot be separately identified from the long run labor wedge and so we normalize it to one. The investment adjustment cost function is assumed to be quadratic and of the form

$$
\phi\left(\frac{x}{k}\right)=\frac{\nu}{2}\left(\frac{x}{k}-\kappa_{j}\right)^{2}
$$

The parameter $\nu$ is set to 2.7 such that Tobin's q is around 4 , and the parameter $\kappa_{j}$ is set such that adjustment costs are zero in steady state for each region.

Some of the parameters of the wedges are easy to identify by using the data or data together with the optimality conditions of the model, helping us reduce the number of parameters that are estimated and improve identification. We use population data for the rest of the world to identify $\eta$ and its AR(1) process, and combined with population data for Latin America and Asia we can identify $n_{L}$ and $n_{A}$ and their autoregressive processes. Table 1 shows the results. Using $\eta_{s s}$, together with the assumption that the world grows at $2 \%\left(z_{s s}=1.02\right)$ and using the growth rate of the model economy we can pin down $\pi_{s s}$. We estimate the remaining efficiency wedge parameters using data on the Solow residual. 
Table 1: Population and Efficiency Wedge Parameters

\begin{tabular}{|c|c|c|c|}
\hline Parameter & Value & Parameter & Value \\
\hline$\pi_{s s}$ & 1.0085 & $\rho_{L}^{a}$ & 0.99 \\
\hline$\eta_{s s}$ & 1.0067 & $\rho_{A}^{a}$ & 0.89 \\
\hline$a_{L s s}$ & 0.37 & $\rho_{L}^{n}$ & 0.99 \\
\hline$a_{\text {Ass }}$ & 0.77 & $\rho_{A}^{n}$ & 0.97 \\
\hline$\eta_{L s s}$ & 1.13 & $\sigma_{L}^{n}$ & 0.003 \\
\hline$\eta_{\text {Ass }}$ & 0.29 & $\sigma_{A}^{n}$ & 0.004 \\
\hline
\end{tabular}

Table 2: International and Government Wedge Parameters

\begin{tabular}{|c|c|c|c|c|c|c|c|c|}
\hline \multicolumn{9}{|c|}{ International Wedge } \\
\hline$\psi_{L 0}$ & $\psi_{A 0}$ & $\left(1-\psi_{L 1}\right.$ & & $\left(1-\psi_{A 1}\right.$ & $\mu_{L}^{\tau^{2}}$ & $\mu_{A}^{\tau^{B}}$ & $\sigma_{L}^{\tau^{B}}$ & $\sigma_{A}^{\tau^{B}}$ \\
\hline 0.13 & 0.95 & 0.94 & & 0.94 & $\overline{0.2}$ & 0.36 & 0.03 & 0.02 \\
\hline \multicolumn{9}{|c|}{ Government Wedge } \\
\hline$g_{R s}$ & $g_{L s}$ & $g_{\text {Ass }}$ & $\rho_{R}^{g}$ & $\rho_{L}^{g}$ & $\rho_{A}^{g}$ & $\overline{\sigma_{R}^{g}}$ & $\overline{\sigma_{L}^{g}}$ & $\overline{\sigma_{A}^{g}}$ \\
\hline 0.1 & 0.1 & 0.12 & 0.73 & 0.80 & 0.86 & 0.03 & 0.05 & 0.17 \\
\hline
\end{tabular}

The international wedge can be directly identified using consumption and population data (see Equations 4 and 5), so its straightforward to estimate its $\operatorname{ARMA}(1)$ process, see Table 2 . The AR(1) process for the government wedge can also be estimated directly from the data and the results are in Table 2. We calibrate the steady state of the labor and capital wedges to fit the mean of per-capita hours worked and the capital to output ratio in the data, $\tau_{R s s}^{h}=1.9, \tau_{L s s}^{h}=0.84, \tau_{A s s}^{h}=1.17, \tau_{R s s}^{k}=0.96, \tau_{L s s}^{k}=0.95, \tau_{A s s}^{k}=$ 0.99 .

The remaining parameters are estimated using Bayesian methods (see An and Schorfheide (2007)). The only difference between using maximum likelihood and a Bayesian estimation is that instead of using a flat prior we choose a particular distribution. Given that we are estimating many parameters, going this route helps the algorithm start its search around the right region. Figure 16 in Appendix C shows a plot of the prior distributions, posterior distributions and modes of the estimation. From that figure it can be seen that our chosen priors are not restrictive with the estimated parameters reflecting the information contained in the data.

The linearized equations of the model combined with the linearized measurement equations form a state-space representation of the model. We apply the Kalman filter to compute the likelihood of the data given the model and to obtain the paths of the wedges. We combine the likelihood function $L\left(Y^{\text {Data }} \mid p\right)$, where $p$ is the parameter 
Table 3: Prior and posterior distributions of wedge parameters

\begin{tabular}{|c|ccc|cc|}
\hline Parameter & \multicolumn{3}{|c|}{ Prior } & \multicolumn{2}{c|}{ Posterior } \\
\hline & Distribution & Mean & S.D. & Mean & Mode \\
$\rho_{R}^{\tau^{h}}$ & Beta & 0.90 & 0.09 & 0.99 & 0.99 \\
$\rho_{L}^{\tau^{h}}$ & Beta & 0.90 & 0.09 & 0.99 & 0.99 \\
$\rho_{A}^{\tau^{h}}$ & Beta & 0.90 & 0.09 & 0.97 & 0.99 \\
$\rho_{R}^{\tau^{K}}$ & Beta & 0.99 & 0.01 & 0.98 & 0.98 \\
$\rho_{L}^{\tau^{K}}$ & Beta & 0.90 & 0.09 & 0.83 & 0.83 \\
$\rho_{A}^{\tau^{K}}$ & Beta & 0.90 & 0.09 & 0.73 & 0.76 \\
$\sigma_{\pi}$ & IGamma & 0.02 & 0.01 & 0.02 & 0.01 \\
$\sigma_{L}^{a}$ & IGamma & 0.03 & 0.01 & 0.03 & 0.03 \\
$\sigma_{A}^{a}$ & IGamma & 0.03 & 0.01 & 0.03 & 0.03 \\
$\sigma_{R}^{\tau^{h}}$ & IGamma & 0.02 & 0.02 & 0.02 & 0.02 \\
$\sigma_{L}^{\tau^{h}}$ & IGamma & 0.03 & 0.02 & 0.04 & 0.04 \\
$\sigma_{A}^{\tau^{h}}$ & IGamma & 0.03 & 0.02 & 0.04 & 0.04 \\
$\sigma_{R}^{\tau^{K}}$ & IGamma & 0.01 & 0.02 & 0.00 & 0.00 \\
$\sigma_{L}^{\tau^{K}}$ & IGamma & 0.02 & 0.02 & 0.01 & 0.01 \\
$\sigma_{A}^{\tau^{K}}$ & IGamma & 0.03 & 0.02 & 0.02 & 0.01 \\
\hline
\end{tabular}

vector, with a set of priors $\pi_{0}(p)$ to obtain the posterior distribution of the parameters $\pi\left(p \mid Y^{D a t a}\right)=L\left(Y^{\text {Data }} \mid p\right) \pi_{0}(p)$. We use the Random-Walk Metropolis-Hastings implementation of the MCMC algorithm to compute the posterior distribution. Table 3 reports the prior and posterior distributions of the persistence and variance parameters of the wedges that we estimate.

By construction, our model explains $100 \%$ of the variation in the data and thus provides the decomposition we need for the business cycle accounting exercise.

Above, we imposed strong restrictions on the interaction between the stochastic processes for the individual wedges. This was because the number of parameters of the covariance matrix of the wedges was very large. Nonetheless, with estimates of the wedges in hand, we can assess this assumption by looking at their empirical relationship. Economically, the correlations between the wedges are typically small with roughly $80 \%$ of the parameters in the correlation matrix less than 0.2 in absolute value. The largest correlations tend to be associated with the cross country relationships between population and productivity.

Below, we will experiment with shutting down the international, capital and labor wedges, with a focus on those wedges specific to Latin America and Asia. As a result, 
we are mostly concerned with interactions between these wedges and all other wedges. One way to assess this is to compute the principal components of the covariance matrix of the wedges. The first four principal components explain almost $85 \%$ of the variation in the data. Of these, the first principal component, which explains roughly $56 \%$ of the variation in the data, loads primarily on the population and productivity wedges of all three regions. The third principal component, which explains $7 \%$ of the variation in the data, load primarily on the rest of the world's government wedge, while the fourth principal component explains another $7 \%$ and load primarily on the Latin American international wedge. Only the second principal component, which explains roughly $16 \%$ of the variation in the data, suggests interactions across wedges, and it loads primarily on the government wedge for Latin America and the capital wedge for the rest of the world.

\section{$6 \quad$ Results}

This section describes the realizations of the wedge processes for the three regions and discusses these patterns within the context of research on international capital market distortions, domestic capital market distortions, and domestic labor market distortions.

\subsection{Behavior of the Wedges}

The following figures depict the model estimates of the pseudo social planners wedges, along with the predicted future path of these wedges estimated from the data.

\subsubsection{Efficiency Wedges}

Figure 3 reports our estimates of total factor productivity - the efficiency wedge - across the three economies. The figure shows that Asia's productivity catches up with the ROW during the first two decades while Latin America does not. This further suggests capital should have flowed in to Asia in the early decades.

\subsubsection{Labor Wedges}

Figure 4 reports our estimate of the labor wedge $1-\tau^{h}$. Recall that this is identified off the relationship between consumption and hours worked in equation (1). A number 
Figure 3: Efficiency Wedges

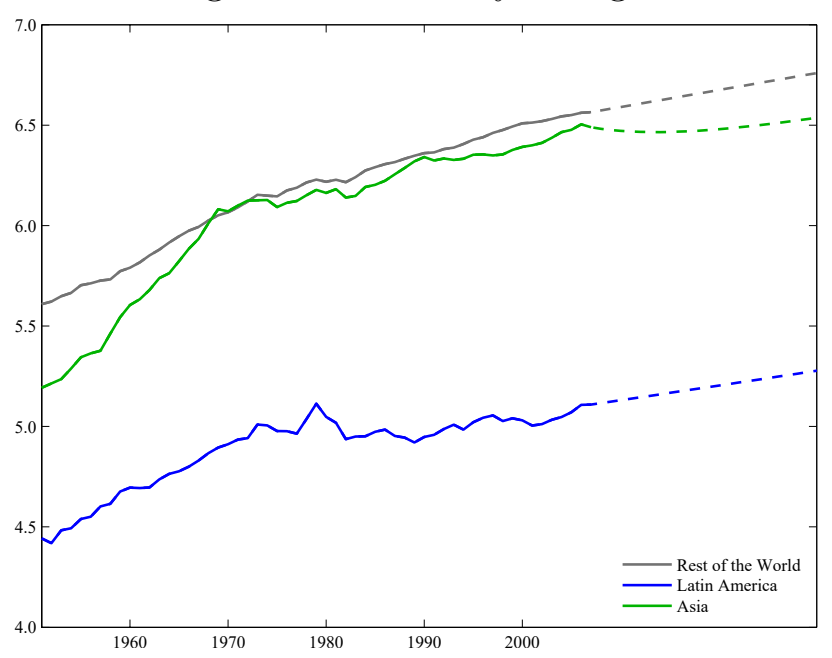

greater than one here denotes employment at levels greater than predicted by the model, which is interpreted as a subsidy to labor; a number less than one identifies relatively low employment which is interpreted as frictions that have effects analogous to a labor tax. The Figure shows that Latin America faced larger labor wedges than all other regions in the early decades of this period, although these labor wedges improve declined after 1970. Asia started with modest labor wedges that improved quickly, while the labor wedge for the rest of the world deteriorates during the first thirty years and then remains constant. These patterns are largely identified of movements in hours worked per capita (plotted in Figure 14 in the appendix).

To interpret the labor wedge, note that this wedge reflects various factors that impact the relationship between the household's marginal rate of substitution between consumption and leisure and the marginal product of labor. These include changes in labor and consumption taxes, (see Chari, Kehoe, and McGrattan (2007), Ohanian, Raffo, and Rogerson (2008)), changes in employment protection laws and other restrictions on hiring or firing that are broadly identified as labor market rigidities (see Cole and Ohanian (2015)), changes in unemployment benefits policies (see Cole and Ohanian (2002)), and changes in product markets that affect firm monopoly power (see Chari, Kehoe, and McGrattan (2007)). Of these factors, those that have received the most attention using cross-country/panel data are changes in taxes and changes in labor market rigidities. We find a number of similarities between the labor wedge estimated here and results from studies of specific labor market distortions and taxes that suggest that our estimated labor wedge is reasonably capturing policy changes that impact the 
labor market.

The declining Latin American and Asian labor wedges are consistent with a number of studies of labor market reforms in these regions. For Asia, several authors discuss various policy reforms, as well as shifts in vocational education and K-12 education, all of which are perceived to have impacted the operation of East Asian labor markets and thus would affect the Asian labor wedge. See, for example, Kim (1990), Kim et a (1980), Mcginn (1980), Cooney et al (2002) and Ohkawa et al (1973). There are also several analyses of Latin American labor markets and labor market reforms, including Heckman and Pages (2004), Murillo (2001) and Duryea and Szekely (2001).

In terms of taxes, studies have documented and analyzed changes in labor income and consumption taxes as these factors impact the labor wedge over the period that we study. Given data availability, these studies are largely limited to the OECD countries, which include many of the countries in our ROW category. Prescott (2002) and Ohanian, Raffo, and Rogerson (2008) report that in most European countries consumption and labor taxes rose substantially between 1950 and the mid-1980s, and then were roughly stable on average after that. To compare these findings to our estimated ROW labor wedge, note that our ROW labor wedge will be averaged over these European countries and over other OECD countries that did not have large tax changes, such as the U.S. and Canada. Given this pattern of large changes in European countries, and small changes in the other ROW countries, it is plausible that movements in our ROW average may indeed reflect the large tax increases that occurred in Europe. From this perspective, we find a strong similarity between our ROW labor wedge and the tax-wedge results from Prescott (2002) and Ohanian, Raffo, and Rogerson (2006).

In terms of labor market rigidities, and distortions, there are a number of studies that construct measures of these distortions across countries. To our knowledge, the most comprehensive study in terms of the number of countries and years is by Campos and Nugent (2009), who construct a panel dataset from 145 countries between 1950 and 2004 of a de jure employment law rigidity index. Their approach is similar to that of Botero, Djankov, La Porta, Lopez-de-Silanes, and Shleifer (2004), who identify labor market rigidities based on employment, collective bargaining, and social security laws. However, unlike the Botero et al analysis, the Campos and Nugent data spans the full period of time that we analyze. We are unaware of other measures of labor market distortions that cover the full period which we study.

Our measure of labor wedges has some qualitatively similar patters to those reported by 
Figure 4: Labor Wedges

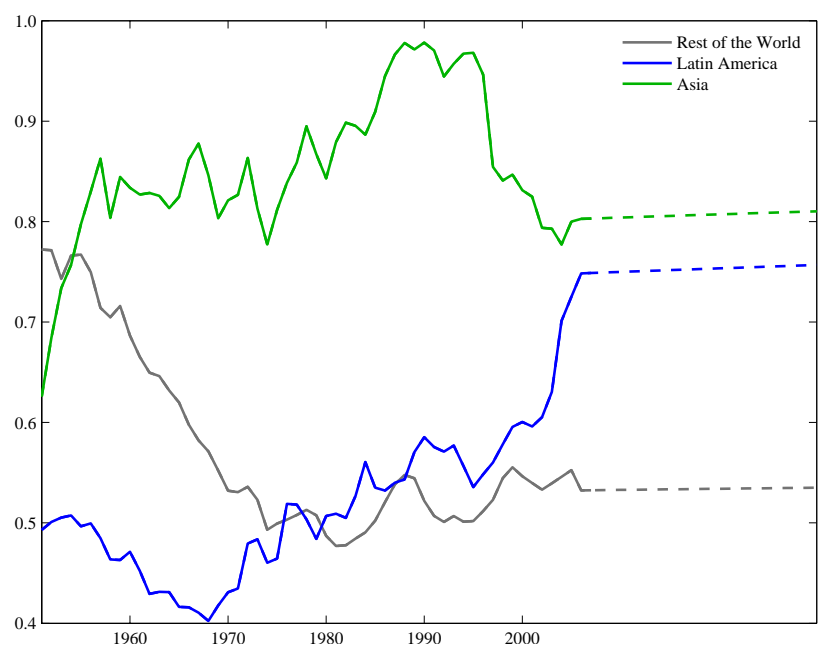

Campos and Nugent (2009). Specifically, Campos and Nugent's measure of aggregated Latin American labor market rigidity shows gradual and modest improvement in terms of declining rigidity from the 1960s until the mid-1990s, and then shows considerably lower rigidity from 1995-2004. Our Latin American labor wedge is qualitatively very similar, as it declines moderately between the 1960s to the mid-1990s, and then declines considerably between the mid-1990s and 2004. The Campos and Nugent measure of aggregated European labor market rigidity shows increased rigidity from the 1950s up until the mid-1980s. This is qualitatively similar to the rest of the world labor wedge, which increases from the 1950s until the mid-1980s. For Asia, Campos and Nugent report an increase in rigidity after the mid-1990's and little change before that. Our Asian labor wedge increases after the mid-1990s, which is qualitatively similar to Campos and Nugent. However, our Asian labor wedge declines considerably before then. This likely reflects factors that are not considered by Campos and Nugent, such as the migration of labor from rural areas, in which labor markets may not be as efficient, to more urban areas.

\subsubsection{Domestic Capital Wedges}

Figure 5 presents our estimates of the capital wedge $1-\tau^{h}$. Recall that this wedge affects the Euler equation (2); it thus reflects the difference between returns to investment estimated from the marginal product of capital, and the return to savings estimated from the growth rate of consumption. We interpret this wedge as an estimate of domestic 
capital market distortions. The ROW and Latin America have a capital tax (a wedge less than one), while Asia starts with an increasing distortion that falls dramatically between 1960 and 1980. Latin America is estimated as having larger domestic capital market distortions through the mid 1980's, to then fall in between those of Asia and ROW. Figures 4 and 5 together suggest that domestic factor market distortions in Asia were relatively large at the beginning of the sample, and declined quickly throughout the middle decades of the sample. This is one potential explanation for the relatively low capital flows into Asia during this period.

The IMF has surveyed changes in capital market regulations and restrictions for a number of countries between 1973 and 2005, and have ranked a number of financial market indicators, including credit controls, interest controls, privatization of banks, entry barriers to banking, banking supervision, bank reserve and requirements. They score these indicators on a ranking between 0-4, which ranges between fully repressed (0) to fully liberalized (4). Their database provides a time series of these scores, as well as indicators of reforms, major reforms, reversals, or major reversals in these individual policies for each year.

The changes in capital market regulations and restrictions constructed by the IMF are plausibly related to the operation of financial markets and therefore should also be related to the estimate capital wedges, with improvement in regulations and restrictions being associated with a narrower capital wedge. Since there is no direct mapping between the IMF measures and the capital wedges, we compare whether the trends in our estimates of capital wedges line up with the trends the IMF measures of capital market. We find that they do.

We summarize the pattern of the IMF evaluations for the four largest Latin American countries: Argentina, Brazil, Chile, and Mexico. These countries adopted a number of financial liberalization reforms throughout this period, with the exception of the early to mid 1980s, which coincides with the Latin American debt crisis. This pattern of trend improvement in capital market regulations and restrictions, with some reversal in the $1980 \mathrm{~s}$, is consistent with the estimated capital wedge of Latin America.

Specifically, in 1973, Argentina, Brazil, and Chilean financial markets were ranked as "fully repressed", and Mexico was ranked as "partially repressed". These countries then implemented reforms in the 1970s that were fairly similar, with less reliance on interest rate controls, more market-based securities market policies, increased privatization of banks, and increased banking supervision. The debt crises of the 1980s saw a tem- 
porary reversal of these policy shifts, particularly on interest rate controls and credit controls. Following the 1980s, however, Latin America made further progress in the operation of their capital markets, including the reduction of entry barriers, further privatization of commercial banks, less reliance on interest rate and credit controls, and more market-based security market policies. By 2005, these countries primarily all had composite rankings that ranged between fully liberalized and partially liberalized financial markets.

The IMF qualitative assessment dovetails with our quantitative estimates of the capital wedge. Specifically, the Latin American capital wedge narrows in the 1970s, it then widens very slightly in the early-mid 1980s, which is the period of some policy reversals, and then it narrows again over the remainder of the period as Latin American implements additional financial market reforms.

For Asia, we summarize changes for Hong Kong, Japan, Singapore, Taiwan, and South Korea, and compare these patterns to our estimates of the Asian capital wedge. In 1973, the IMF ranked the financial markets of Taiwan as fully repressed, those of Japan as partially repressed, and those of Hong Kong and Singapore as partially liberalized. The 1970s and 1980s saw all of these countries liberalize security market policies, and impose fewer controls on interest rates and credit levels. By 2005, all countries were ranked as fully liberalized or close to fully liberalized. These patterns dovetail with our estimated capital wedges for Asia, which shows a trend narrowing of the wedge over this same period. This narrowing is consistent with the persistent improvement in financial market liberalization enacted by these Asian countries over this period.

\subsubsection{International Wedges}

We begin this subsection by noting that it is well known that institutional factors have played a key role in the adoption and subsequent removal of capital controls and other regulatory impediments to international capital flows. Previous research, however, has found it difficult to quantify the size of these distortions. Specifically, measuring the effective size of these controls within an economic model context, much less quantifying the impact of these impediments, has been difficult. This reflects the fact that controls, regulations, and international transaction taxes and fees are complicated, they vary considerably over time, and moreover, they may or may not be enforced. ${ }^{2}$ Our estimated

\footnotetext{
${ }^{2}$ To see this, consider the case of Japan, which incorporated substantial regulations and restrictions on capital flows in the postwar period, as their goal was to limit new debt accumulation and thereby not
} 
Figure 5: Domestic Capital Wedges

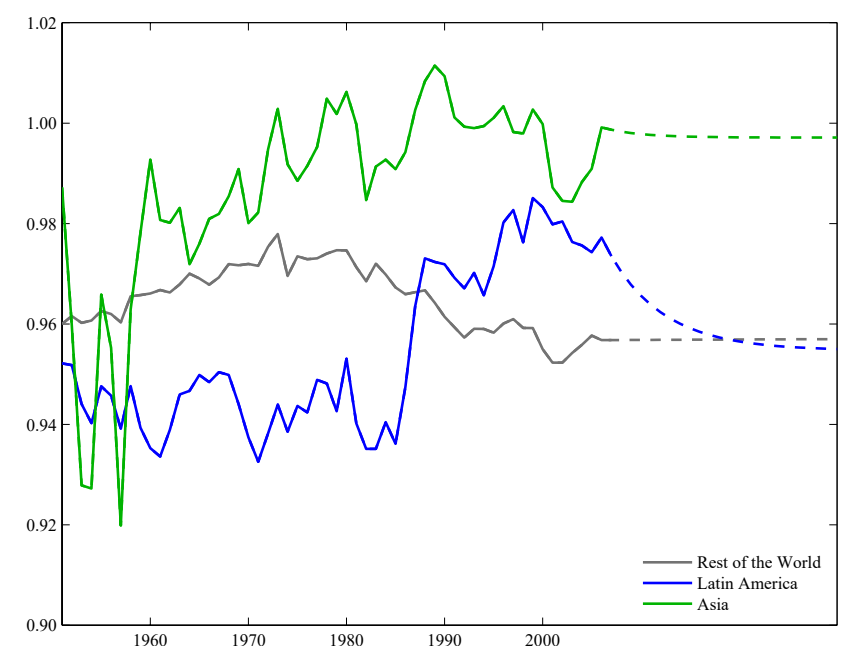

international capital flow wedges provide a measure of the importance of these various complicated controls, taxes, and fees.

The evolution of the international wedge $1-\tau^{b}$, which is identified off relative consumption growth rates from the Euler equation in international asset purchases (3), is depicted in Figures 6 and 7. Figure 6 plots the international wedge from the pseudo planners problem while Figure 7 recovers the international wedge from the competitive equilibrium problem. Note that the competitive equilibrium's international wedge (see Figure7) corresponds to the growth rate of the pseudo planners wedge or what we call cumulative international wedge (see Figure 6). ${ }^{3}$ Since all wedges are relative to the rest of the world, there are only two lines in these Figures.

The cumulative international wedge is directly pinned down by the consumption of a region relative to the rest of the world. Figure 6 shows that Asia's consumption was catching up with the ROW until the mid 1990's while Latin America's was fairly constant up until it started losing ground in 1980 when the debt crises hit (consumption levels are plotted directly in Figure 12 in the appendix). When we recover the compet-

weaken their international credit rating (Pyle (1996)). Restrictive capital controls were in place in the 1950s and 1960s, particularly on foreign direct investment, though on the other hand, Japan encouraged international licensing arrangements to access new technologies. By the late 1960s, Japan's entrance into the OECD required some capital market liberalization. By 1980, broad controls were apparently eliminated, though many international financial transactions were still subject to a variety of specific controls and regulations. In the mid-1980s, the dollar-yen accord created additional liberalization by establishing markets that previously had not existed for some financial instruments.

${ }^{3}$ Appendix A shows the mapping between the competitive equilibrium's international wedge and the pseudo planners problem international wedge. 
Figure 6: Cumulative International Wedges

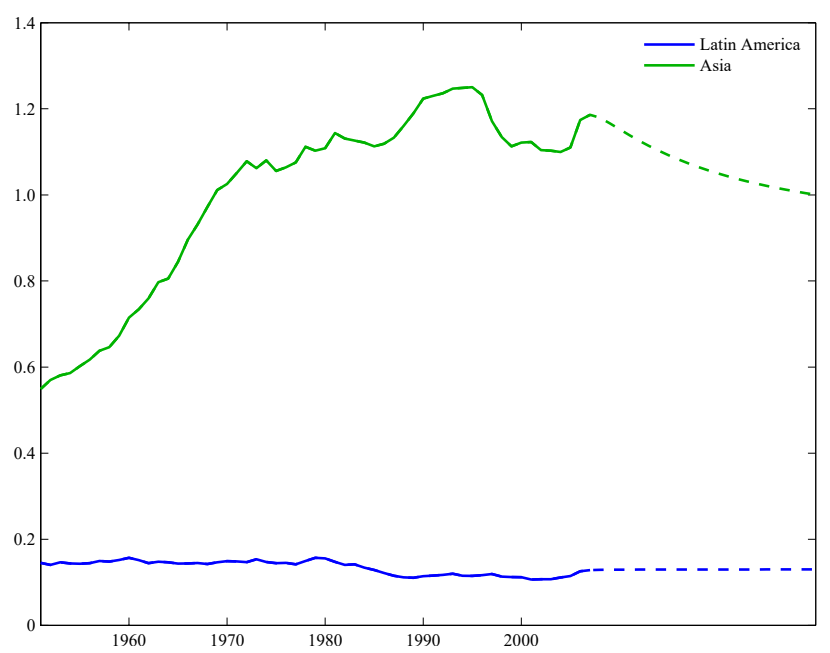

Figure 7: International Wedges

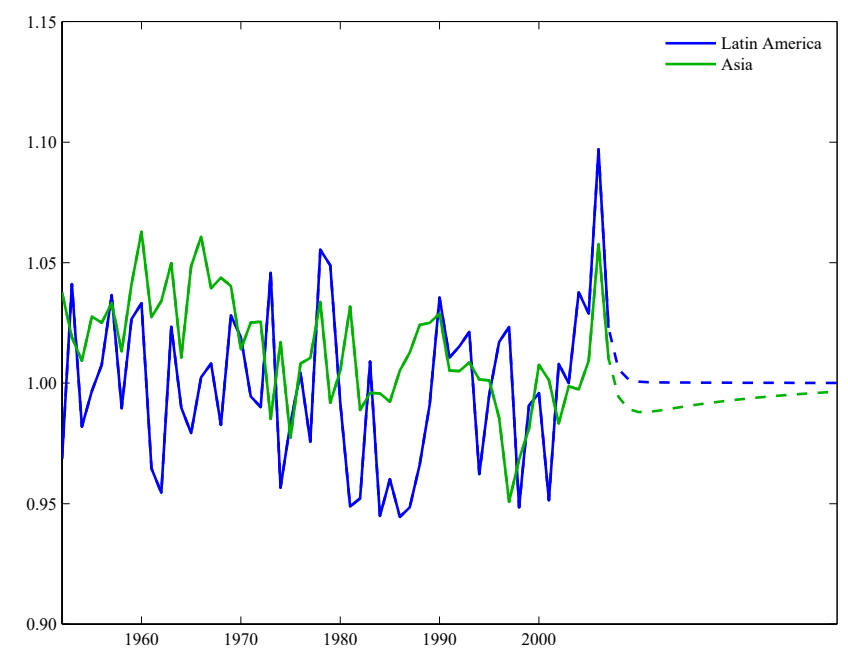

itive equilibrium's international wedge (Figure 7) we see that the international wedge for Asia was greater than one in the early years of the sample. This means that Asia was faced with a tax on borrowing (or alternatively a subsidy on international savings) in the early years of the period (a number greater than one makes repayments on debts larger and hence more negative, and increases the return on foreign savings). Latin America, by contrast, had wedges that were frequently negative during this period, which acts as a subsidy on borrowing.

By the 1990s these wedges had largely converged. This is consistent with the pattern identified in Figure 1 which shows that capital flows to the two regions become more synchronized towards the end of the sample. Overall, the results for the international 
wedge are supportive of a role for capital controls, or other frictions in international capital markets, in discouraging capital flows into Asia and encouraging flows into Latin America, specially during the first twenty years of the sample.

\subsection{Counterfactuals and Decompositions}

We now study the quantitative importance of international capital imperfections (the international wedge), domestic capital imperfections (the capital wedge), and labor market imperfections (the labor wedge) on economic outcomes, focusing on capital flows, by shutting down movements in these distortions one at a time.

As in Chari, Kehoe and McGrattan (2007), to evaluate the effect of movements in the labor and capital wedges, we treat them parametrically and fix them at their initial values. To quantify the impact of changes in international capital market imperfections, we also treat the international wedge parametrically but fix its value to zero (or $1-\tau^{b}=$ 0) since a non-zero value would lead to degenerate long run relative consumption levels. Note that every time we remove a wedge (fix it to its initial value) we have to re-solve the model so that agent expectations reflect the assumptions of the counterfactual experiment. The order in which we remove a wedge matters for the results, ${ }^{4}$ and there are more than forty thousand ways (orderings) in which we can remove them. For computational reasons we will approximate this number by removing the wedges in random order ten thousand times, and then average over all of these combinations.

Figures 8 and 9 show the results of these counterfactual experiments for Latin American and Asian capital flows, as measured by the ratio of net exports to output, respectively. In each period, the effect of all wedges in absolute value accounts for a $100 \%$ of the change in net-exports (the sum of the bars). A negative bar, means that had that wedge not been there, then there would have been capital inflows to the region. A positive bar, means that had that wedge not been in place then there would have been capital outflows from the region. As a result, the sign of the bar chart indicates the direction in which each wedge was affecting capital flows, and in each year we can see the relative importance of each wedge in explaining capital flows. Furthermore, the graphs also show what would have happened to the direction of capital flows if none of the eight wedges were present. By removing the negative fraction of each bar from

\footnotetext{
${ }^{4}$ For example, the marginal contribution of the labor wedge is different if the capital wedge has been previously removed than if the international wedge has been previously removed.
} 
the positive, if the outcome is positive, then capital would have flown out and if the outcome is negative then capital would have flown in.

Figure 8 shows the contribution of movements in Latin American wedges, as well as an aggregate of all other wedges, on Latin American net-exports. We can see that throughout the first half of the period, the Latin American capital wedge (dark blue bars) and international wedge (green bars) were promoting capital inflows, while the labor wedge (light blue bars) was preventing even more capital from flowing in. During the second half of the period the roles of the wedges reverse. Their capital and international wedge were preventing capital from flowing into Latin America and the labor wedge was promoting capital inflow.

The intuition behind these results is as follows. The Latin American labor wedge in the initial period is low compared to its values in the first half of the period and then its high. Thus, fixing the Latin American labor wedge at its initial level initially reduces and then increases the price of labor. Consequently, while the cost of labor is relatively low, Latin American hours worked and investment rise, attracting capital flows to finance a consumption boom. Then, when the cost of labor becomes relatively high, hours worked and investment decrease causing consumption to contract and capital to flow out. The pattern of the capital wedge in Latin America implies that the initial value is lower than values for the remainder of the 1950s through the 1980s. This means that through the 1980s the cost of capital is lower, generating a large increase in investment and hours worked that is enough to increase consumption and save abroad. After the 1980s, investment and hours flatten out and there are capital inflows to smooth consumption.

Interestingly, we see, that during the Latin American debt crises, the capital flow reversal that we observed would have been even larger if these frictions were not in place. Overall, we find that if we were to remove all domestic and international frictions, then Latin America would have received even larger inflows during the first decade and then would have experienced capital outflows.

Figure 9 shows the results of the counterfactual exercises for Asian net-exports. There are two graphs in the figure. The first graph shows the effect of removing the Asian capital, labor and international wedges, while the second graph shows the result of removing the labor and capital wedge for the ROW. As we can see from the figure, during the first decade, the Asian international wedge (green bars) was preventing capital from flowing into Asia but quantitatively was not playing a central role. After 
Figure 8: Net-Exports Counterfactuals for Latin America

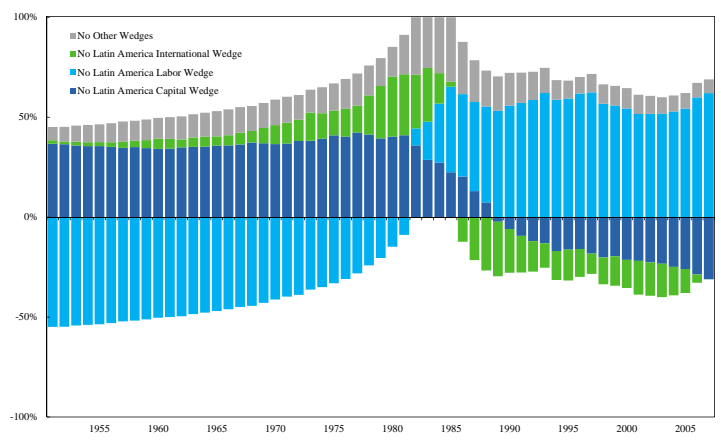

1963, the Asian international wedge was actually encouraging capital to flow into the region. This is expected as the international wedge for Asia reflects a tax on borrowing that relaxes after the first twenty years of the sample (see Figure 7).

From the first graph of Figure 9, we can see that the Asian labor wedge (the light blue bars) plays a much more prominent role during the first two decades, and that it was preventing capital from flowing in throughout the whole period. Note that by fixing the Asian labor wedge to its initial value, we are imposing a comparatively high distortion on labor markets, as this wedge declines by about 35 percent over time. This implies that in the counterfactual, labor input is reduced which in turn reduces incentives to invest in Asia. As a result, output and labor fall considerably compared to the data, and Asia receives substantial capital inflows which are used to smooth consumption. The role of the Asian capital wedge (the dark blue bars) is smaller than that of the labor wedge, but it was encouraging capital inflows through the first half of the period and preventing capital from flowing in towards the end. For Asia, the initial capital wedge is low relative to its value for the rest of the 1950s through the 1970s and the intuition behind its effect its very much the same as for the Latin American counterfactual. Finally, we can see that all other wedges from Latin America and the ROW (the grey bars) played a significant role in preventing capital inflows to Asia, specially during the first twenty years.

The second graph of Figure 9 expands on this result. It shows that the capital wedge for the ROW (dark blue bars) was preventing capital from flowing into Asia for the first two decades and a half, while the ROW's labor wedge (light blue bars) was fostering capital 
Figure 9: Net-Exports Counterfactuals for Asia
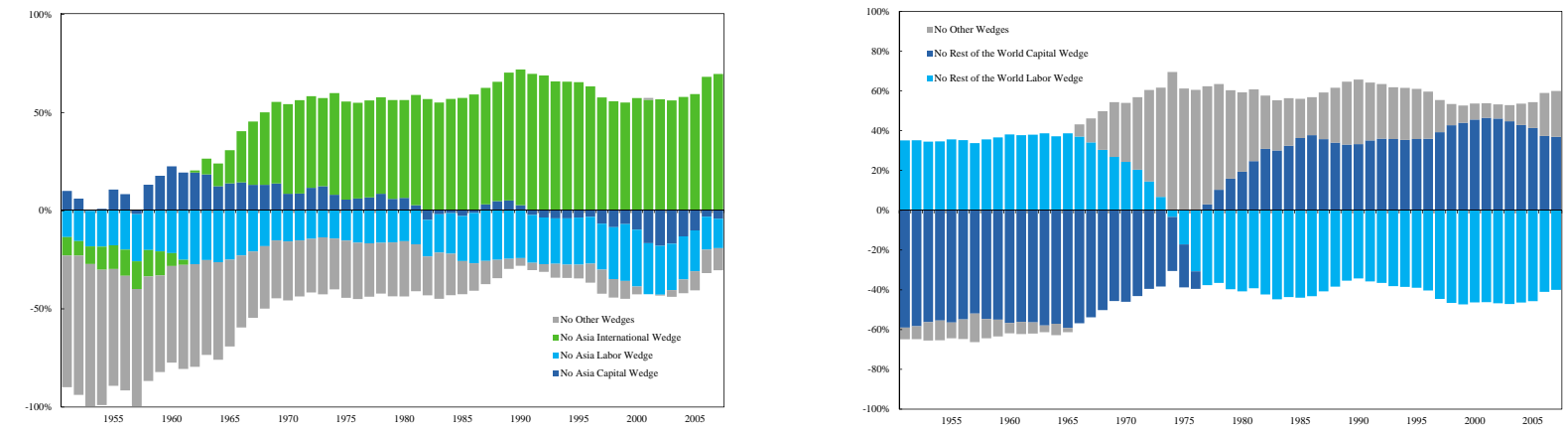

inflows. However the effect of the capital wedge was larger, meaning that domestic wedges for the ROW where preventing capital from flowing into Asia for this earlier part of the period. This result shows the importance of general equilibrium effects for understanding the direction of capital flows.

These results are surprising, in that Latin American capital flows have primarily been affected by domestic factors, and in particular labor market factors, rather than international capital market factors. Similarly, international capital market factors are not the key factor driving Asian capital flows, during the 1950s and 1960s when Asia was growing very rapidly and when their international capital markets were distorted. It is not until the 1970s and afterwards, when Asia has removed many impediments to capital flows, that these factors are quantitatively important in Asia.

We complement the previous results with Tables 4 and 5 to summarize the absolute relative contribution of the labor, capital and international wedges for capital flows in each decade of our sample. Each number in each table is the decade average of the absolute marginal contribution of each wedge over the sum of the marginal contributions of all labor, capital and international wedges.

Table 4 shows the results for Latin America. As we can see during the 50s and 60s, domestic distortions (the labor wedge $\tau_{L}^{h}$ plus the capital wedge $\tau_{L}^{k}$ ) explain between $48 \%$ and $55 \%$ of the movements in capital flows, while international distortions (the international wedge $\tau_{L}^{B}$ ) only explain between $3 \%$ and $6 \%$.

Table 5 shows that for Asia, during the decade of the 1950s domestic distortions $\left(\tau_{A}^{h}\right.$ plus $\left.\tau_{A}^{k}\right)$ were three times more important than international distortions $\left(\tau_{A}^{B}\right)$ and during the 
Table 4: Contribution of the different wedges for Latin American Net-Exports, by decade.

\begin{tabular}{|c|c|c|c|c|c|c|}
\hline Wedge Contributions & $1950 \mathrm{~s}$ & $1960 \mathrm{~s}$ & $1970 \mathrm{~s}$ & $1980 \mathrm{~s}$ & $1990 \mathrm{~s}$ & $2000 \mathrm{~s}$ \\
\hline \hline$\tau_{R}^{h}$ & 0.17 & 0.17 & 0.15 & 0.14 & 0.12 & 0.13 \\
\hline$\tau_{L}^{h}$ & 0.36 & 0.30 & 0.25 & 0.27 & 0.38 & 0.38 \\
\hline$\tau_{A}^{h}$ & 0.04 & 0.05 & 0.06 & 0.07 & 0.05 & 0.03 \\
\hline$\tau_{R}^{k}$ & 0.15 & 0.15 & 0.14 & 0.13 & 0.15 & 0.15 \\
\hline$\tau_{L}^{k}$ & 0.19 & 0.18 & 0.18 & 0.13 & 0.10 & 0.16 \\
\hline$\tau_{A}^{k}$ & 0.03 & 0.04 & 0.04 & 0.05 & 0.03 & 0.02 \\
\hline$\tau_{L}^{B}$ & 0.03 & 0.06 & 0.12 & 0.13 & 0.11 & 0.09 \\
\hline$\tau_{A}^{B}$ & 0.03 & 0.04 & 0.07 & 0.08 & 0.06 & 0.04 \\
\hline
\end{tabular}

Table 5: Contribution of the different wedges for Asian Net-Exports, by decade.

\begin{tabular}{|c|c|c|c|c|c|c|}
\hline Wedge Contributions & $1950 \mathrm{~s}$ & $1960 \mathrm{~s}$ & $1970 \mathrm{~s}$ & $1980 \mathrm{~s}$ & $1990 \mathrm{~s}$ & $2000 \mathrm{~s}$ \\
\hline \hline$\tau_{R}^{h}$ & 0.21 & 0.18 & 0.15 & 0.23 & 0.25 & 0.29 \\
\hline$\tau_{L}^{h}$ & 0.11 & 0.10 & 0.08 & 0.08 & 0.06 & 0.06 \\
\hline$\tau_{A}^{h}$ & 0.10 & 0.14 & 0.12 & 0.12 & 0.11 & 0.07 \\
\hline$\tau_{R}^{k}$ & 0.41 & 0.30 & 0.15 & 0.19 & 0.24 & 0.28 \\
\hline$\tau_{L}^{k}$ & 0.07 & 0.06 & 0.06 & 0.04 & 0.03 & 0.04 \\
\hline$\tau_{A}^{k}$ & 0.05 & 0.07 & 0.05 & 0.02 & 0.02 & 0.04 \\
\hline$\tau_{L}^{B}$ & 0.01 & 0.02 & 0.03 & 0.02 & 0.02 & 0.02 \\
\hline$\tau_{A}^{B}$ & 0.04 & 0.13 & 0.34 & 0.31 & 0.28 & 0.20 \\
\hline
\end{tabular}

1960s domestic distortions explained $21 \%$ percent of capital flows while international distortions only explained $13 \%$. Towards the end of the sample international capital imperfections become between two and three times more important than domestic imperfections.

Finally, to further emphasize the importance of general equilibrium effects, Figure 10 shows the effect that different wedges have on the ROW consumption. We can see that the Latin American labor wedge (light blue bars) was encouraging consumption in the ROW up until 1980 and then discouraging it. Asia's international wedge (green bars) was discouraging consumption since 1965. Note that the effect of these two wedges plus the aggregate of the other wedges for Asia and Latin America (the grey bars) dominates the net effect of their own wedges (the yellow bars). 
Figure 10: Consumption Counterfactuals for ROW

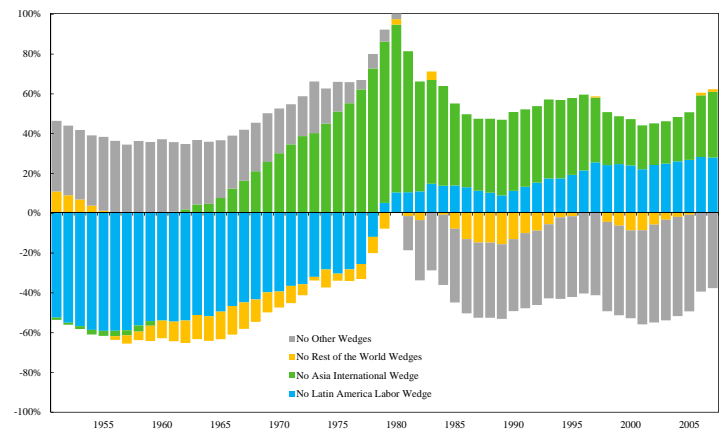

\section{Summary and Conclusion}

Between 1950 and today, Asia grew much faster than Latin America, but received less international capital. This is surprising because all else equal, rapidly growing countries should generate higher capital returns and thus should receive more capital than slow growing countries. Some studies implicitly adopt the "all else equal" aspect of this argument, and analyze capital flow patterns by focusing on imperfections and inefficiencies of international capital markets that either depress the incentives, or limit the opportunities, to move capital to fast growing regions. In this paper, we abandoned the "all else equal" assumption and explored the role of domestic factor market distortions in influencing the return to capital and the incentives for capital flows.

The paper first shows that domestic labor market and capital market distortions affect capital flows to rapidly growing regions by either impacting the marginal product of capital, or by impacting the return to capital net of its marginal product. It also shows that labor market distortions only affect these returns out of steady state, which implies that studies based on long-run averages will not detect the evidence of labor distortions, even when they are present. The paper then constructs a dataset of output, consumption, investment, labor, capital stocks, and international capital flows for Asia, Latin America, and the Rest of the World, and develops an open-economy DSGE model of these regions that features an open-economy version of business cycle accounting. We use this framework and these data to measure domestic labor and domestic capital market distortions, and international capital market distortions, and to quantify the 
impact of these factors on international capital flows.

We find that domestic distortions, which have not been closely studied in the literature, have very large effects on capital flows, and that the general equilibrium effects of these distortions is also very large, as changes in domestic labor and capital market distortions spill over and affect economic activity in other parts of the world. Domestic and international labor wedges, and Rest of the World capital market distortions, are the primary drivers of Asian capital flows for much of the period. Surprisingly, the impact of international capital market distortions are not quantitatively important during the 1950s and 1960s when Asia was growing very quickly. Latin American capital flows are driven primarily by the Latin American labor wedge. International capital market distortions have relatively small effects on Latin American capital flows, with the exception of the period around the Latin American debt crises.

These findings have both positive and normative implications. On the positive side, the results indicate that there is no presumption that rapidly growing countries should receive disproportionately high capital flows, as domestic labor and capital market distortions, and the general equilibrium effects of these distortions, can sufficiently depress the incentives to move capital to these countries. On the normative side, our findings also suggest that the welfare effects of reforming domestic institutions can be much larger than often assumed, as changes in domestic distortions can have large direct and indirect affects on world allocations.

\section{References}

1. An, Sungbae and Frank Schorfheide. 2007. "Bayesian analysis of dsge models." Econometric Reviews, 26(2-4):113-172.

2. Bayoumi, Tamim and Andrew K. Rose. 1993. "Domestic savings and intranational capital flows." European Economic Review, 37:6, pp. 1197-202.

3. Barelli P, de Abreu Pessôa S. 2003. Inada conditions imply that production function must be asymptotically Cobb-Douglas. Economics Letters 81: 361-63.

4. Botero, Juan \& Simeon Djankov \& Rafael Porta \& Florencio C. Lopez-De-Silanes, 2004. "The Regulation of Labor," The Quarterly Journal of Economics, MIT Press, vol. 119(4), pages 1339-1382, November. 
5. Campos, Nauro F and Jeffrey B. Nugent. 2012. "The Dynamics of the Regulation of Labor in Developing and Developed Countries since 1960," IZA discussion paper number 6881, Bonn, Germany.

6. Caselli, Francesco and James Feyrer. 2007. "The Marginal Product of Capital." Quarterly Journal of Economics, 122:2, pp. 535-68.

7. Chari VV, Kehoe PJ, McGrattan ER. 2007. Business Cycle Accounting. Econometrica 75: 781-836.

8. Cole, Harold L. \& Lee E. Ohanian, 2002. "The Great U.K. Depression: A Puzzle and Possible Resolution," Review of Economic Dynamics, Elsevier for the Society for Economic Dynamics, vol. 5(1), pages 19-44, January.

9. Cole, Harold L. \& Lee E. Ohanian, 2015. "The Impact of Cartel, Monetary, and Productivity Shocks on the International Great Depression", discussion paper, UCLA.

10. Dooley, Michael, Jeffrey A. Frankel, and Donald J. Mathieson. 1987. "International Capital Mobility: What Do Saving-Investment Correlations Tell Us?" " IMF Staff Papers, 34:3, pp. 503-30.

11. Duryea, Susanne and Miguel Szekely, Labor Markets in Latin America: A Look at the Supply Side, 2001, Pages 199-228.

12. Eaton, Jonathan \& Gersovitz, Mark, 1981. "Debt with potential repudiation: Theoretical and empirical analysis," The Review of Economic Studies, vol. 48(2), pages 289-309, April.

13. Feldstein, Martin and Charles Yuji Horioka. 1980. "Domestic Saving and International Capital Flows." Economic Journal, 90:358, pp. 314-29.

14. Fernandez-Villaverde, Jesus and Juan F. Rubio-Ramirez. 2007. "Estimating macroeconomic models: A likelihood approach." Review of Economic Studies, 74(4):1059-1087.

15. Frankel, Jeffrey A. 1992. "Measuring International Capital Mobility: A Review." American Economic Review, 82:2, pp. 197-202. 
16. Greenwood, Jeremy, Zvi Hercowitz and Gregory W. Huffman. 1988. "Investment, Capacity Utilization, and the Real Business Cycle." American Economic Review, $78(3), 402-417$.

17. Gourinchas Pierre-Olivier \& Olivier Jeanne, 2013. "Capital Flows to Developing Countries: The Allocation Puzzle," Review of Economic Studies, Oxford University Press, vol. 80(4), pages 1484-1515.

18. Heckman, James J. \& Carmen Pagés, 2004. "Law and Employment: Lessons from Latin American and the Caribbean," NBER Books, National Bureau of Economic Research, Inc.

19. Kehoe PJ, Perri F. 2002. International Business Cycles with Endogenous Incomplete Markets. Econometrica 70: 907-28.

20. C. Kim, "Labor Market Development", in Korean Economic Development, 1990, Greewood Press, NY, Jene Kwon, ed.

21. David Kim, Mahn Je, et al Education and Social Modernization in the Republic of Korea, Harvard University Press, Cambridge, MA 1980

22. Hsieh, Chang-Tai. "Productivity Growth and Factor Prices in East Asia." American Economic Review, 1999, 89(2), pp. 133-38.

23. Law and Labor Market Regulation in East Asia, edited by Sean Cooney, Tim Lindsey, Richard Mitchell, Zhu Ying, 2002, Routledge, London.

24. Litina A, Palivos T. 2008. Do Inada conditions imply that production function must be asymptotically Cobb-Douglas? A comment. Economics Letters 99: 49899

25. Lucas RE, Jr. 1990. Why Doesn't Capital Flow from Rich to Poor Countries? American Economic Review 80: 92-96.

26. McGinn, Noel F. 1980. Education and Development in Korea. Cambridge, MA: Harvard University Press

27. Mitchell, B. R. (2003), International historical statistics (5th edn.; Basingstoke, Hampshire ; New York: Palgrave Macmillan). 
28. Monge-Naranjo, Alexander \& Sanchez, Juan M. \& Santaeulalia-Llopis, Raul. 2015. "Natural Resources And Global Misallocation," Federal Reserve Bank of St. Louis Working Paper 2015-13A.

29. Murillo, Maria Victoria. 2001. Labor Unions, Partisan Coalitions, and Market Reforms in Latin America. New York: Cambridge University Press.

30. Neumeyer, Pablo A. \& Perri, Fabrizio, 2005. "Business cycles in emerging economies: the role of interest rates," Journal of Monetary Economics, Elsevier, vol. 52(2), pages 345-380, March.

31. Ohanian, Lee \& Raffo, Andrea \& Rogerson, Richard, 2008. "Long-term changes in labor supply and taxes: Evidence from OECD countries, 1956-2004," Journal of Monetary Economics, Elsevier, vol. 55(8), pages 1353-1362, November.

32. Ohanian LE, Wright MLJ. 2010. Capital Flows and Macroeconomic Performance: Lessons from the Golden Era of International Finance. American Economic Review 100: 68-72.

33. Ohanian, LE, Wright MLJ 2008. Where Did Capital Flow? Fifty Years of International Rate of Return Differentials and Capital Flows. UCLA Working Paper.

34. Ohkawa K, Rosovsky H. 1973. Japanese economic growth; trend acceleration in the twentieth century. Stanford, Calif.: Stanford University Press. xvi, 327 p. pp.

35. Prescott, Edward C., 2002. "Prosperity and Depression," The American Economic Review, vol. 92(2), pages 1-15, May.

36. Pyo HK. 1996. Historical Statistics of Korea: Investment and Capital Stock. Seoul: Institute of Economic Research, Seoul National University.

37. Rahmati, Mohammad and Jacek Rothert, 2014. "Business Cycle Accounting in a Small Open Economy," Departmental Working Papers 46, United States Naval Academy Department of Economics.

38. Sinn, Stefan. 1992. "Saving-Investment Correlations and Capital Mobility: On the Evidence from Annual Data." Economic Journal, 102:414, pp. 1162-70. 
39. Schmitt-Grohe, Stephanie and Martin Uribe. 2003. "Closing Small Open Economy Models." Journal of International Economics, vol. 61, pages 163-185.

40. Taylor, Alan M. 1996. "International Capital Mobility in History: The SavingInvestment Relationship." NBER Working Paper, 5743.

41. Tesar, Linda L. 1991. "Savings, Investment and International Capital Flows." Journal of International Economics, 31:1-2, pp. 55-78.

42. Young, Alwyn (1995), "The Tyranny of Numbers: Confronting the Statistical Realities of the East Asian Growth Experience", The Quarterly Journal of Economics, 110 (3), 641-80. 


\section{Appendix (Not for publication)}

\section{Appendix A}

Consider a social planner who's problem is to choose state, date and country contingent sequences of $C, K, H$ to maximize

$$
E_{0}\left[\sum_{j} \chi_{j t}^{C} \sum_{t=0}^{\infty} \beta^{t}\left\{\ln \left(\frac{C_{j t}}{N_{j t}}\right)-\chi_{j t}^{I} \chi_{j t}^{H} \frac{\psi}{1+\gamma}\left(\frac{h_{j t} N_{j t}}{N_{j t}}\right)^{1+\gamma}\right\} N_{j t}\right]
$$

subject to a resource constraint for each state and date

$$
\sum_{j}\left\{C_{j t}+\chi_{j t}^{I} X_{j t}+G_{j t}\right\}=\sum_{j} \chi_{j t}^{I} A_{j t} K_{j t}^{\alpha}\left(h_{j t} N_{j t}\right)^{1-\alpha}+T_{t}^{S P}
$$

and the capital evolution equations above. Here the $\chi$ are the social planner version of wedges (as in the competitive equilibrium problem, we normalize $\chi_{R t}^{C}=1$ for all $t$ ). Note that the investment wedge now appears in the utility function and the production function, as well as multiplying investment in the resource constraint.

After substituting and rearranging we obtain the intensive form social planners problem of maximizing

$$
E_{0}\left[\sum_{t=0}^{\infty} \beta^{t}\left(\prod_{s=0}^{t} \eta_{s}\right) \sum_{j} \chi_{j t}^{C}\left\{\ln \left(c_{j t}\right)-\chi_{j t}^{I} \chi_{j t}^{H} \frac{\psi}{1+\gamma} h_{j t}^{1+\gamma}\right\} n_{j t}\right]
$$

subject to sequences of

$$
\sum_{j}\left\{c_{j t}+\chi_{j t}^{I} x_{j t}+g_{j t}\right\}=\sum_{j} \chi_{j t}^{I} a_{j t} \pi_{t} k_{j t}^{\alpha}\left(h_{j t} n_{j t} \eta_{t}\right)^{1-\alpha}+t_{t}^{S P}
$$

and the intensive form capital accumulation equation. The social planner takes the sequences of $t^{S P \prime} s$ as constant. If in equilibrium, we suppose that these transfers "rebate" the "revenues" from the investment wedge, then we can write the sequence of constraints as

$$
\sum_{j}\left\{c_{j t}+z_{t} k_{j t+1}-(1-\delta) k_{t}-\phi\left(\frac{x_{j t}}{k_{j t}}\right) k_{j t}+g_{j t}\right\}=\sum_{j} a_{j t} \pi_{t} k_{j t}^{\alpha}\left(h_{j t} n_{j t} \eta_{t}\right)^{1-\alpha}
$$

The proof that the solution to the pseudo-planners problem attains the equilibrium of 
the competitive equilibrium problem follows from a straightforward comparison of the first order necessary (and sufficient) conditions for an optimum noting that the mapping between competitive equilibrium wedges $\tau$ and social planners wedges $\chi$, for labor and investment are given by

$$
\begin{aligned}
\chi_{j t}^{H} & =\frac{1}{1-\tau_{j t}^{h}}, \\
\frac{\chi_{j t+1}^{C}}{\chi_{j t}^{C}} \frac{\chi_{j t+1}^{I}}{\chi_{j t}^{I}} & =1-\tau_{j t+1}^{K} .
\end{aligned}
$$

For consumption, the first order condition for the social planners problem is

$$
\theta_{j t}=\chi_{j t}^{C}
$$

and so will have the same form as in the CE problem as long as

$$
\ln \chi_{j t+1}^{C}=\left(1-\rho_{j}^{C}\right) \ln \chi_{j S S}^{C}+\rho_{j}^{C} \ln \chi_{j t}^{C}+\varepsilon_{j t+1}^{C},
$$

for $1-\rho_{j}^{C}=\psi_{j 1}$ and $\chi_{j S S}^{C}=\psi_{j 0}$. Importantly, the $\varepsilon_{j t}$ must have an autoregressive structure with the same parameters as the process for $\tau_{j t}^{B}$ (this is because the level of the competitive equilibrium international wedge governs the change in the social planners international wedge).

One last technical difficulty needs to be dealt with. In order to use the pseudo social planners problem to study the effect of interventions in the competitive equilibrium problem, it is in general necessary to alter the initial conditions for the $\chi_{j 0}^{C}$ in the social planners problem. That is, if we want to analyze the effect of an intervention in the competitive equilibrium economy keeping initial wealth constant, it is necessary for $\chi_{j}^{C}$ to "jump" with the intervention. This can be done using the relationship between bonds and real allocations of the intensive form competitive equilibrium problem

$$
b_{j t}=-E\left[n x_{j t}+q_{t, t+1} z_{t} n x_{j, t+1}+q_{t, t+1} q_{t+1, t+2} z_{t} z_{t+1} n x_{j, t+2}+\ldots\right]
$$

where net exports are given by

$$
n x_{j t}=y_{j t}-c_{j t}-x_{j t}-g_{j t} .
$$

We then iterate to find the initial value for $\chi_{j}^{C}$ after the intervention that keeps initial 
wealth constant.

\section{Appendix B}

Data on the expenditure side of the national income and product accounts was taken from a number of different sources as in Ohanian and Wright (2008). In all cases, data in local currency units was used, in both constant and current prices. As a general rule, we began with the OECD Annual National Accounts for industrial countries from 1970 to the present. This was supplemented with the World Bank's World Development Indicators which was used for non-industrial countries for the period 1960 to the present, and for industrial countries between 1960 and 1970. Gaps in these data sources, including data for the period from 1950 to 1960, were filled in first using the World Bank's World Savings Database described in Loayza et al (1999). After this, the United Nations National Accounts database was used. Local curreny unit data from versions 6.2 and 5.6 of the Penn World Tables was then used.

Finally, a number of other official and country specific sources were used to fill in remaining gaps. In a small number of cases, data on the expenditure accounts in current values was used along with the GDP deflator to fill in remaining gaps. The list of specific sources of data for Latin America and East Asia that we consulted are below.

Figures 11 to 15 show plots of the data used in the estimation. 
Figure 11: Gross Domestic Product

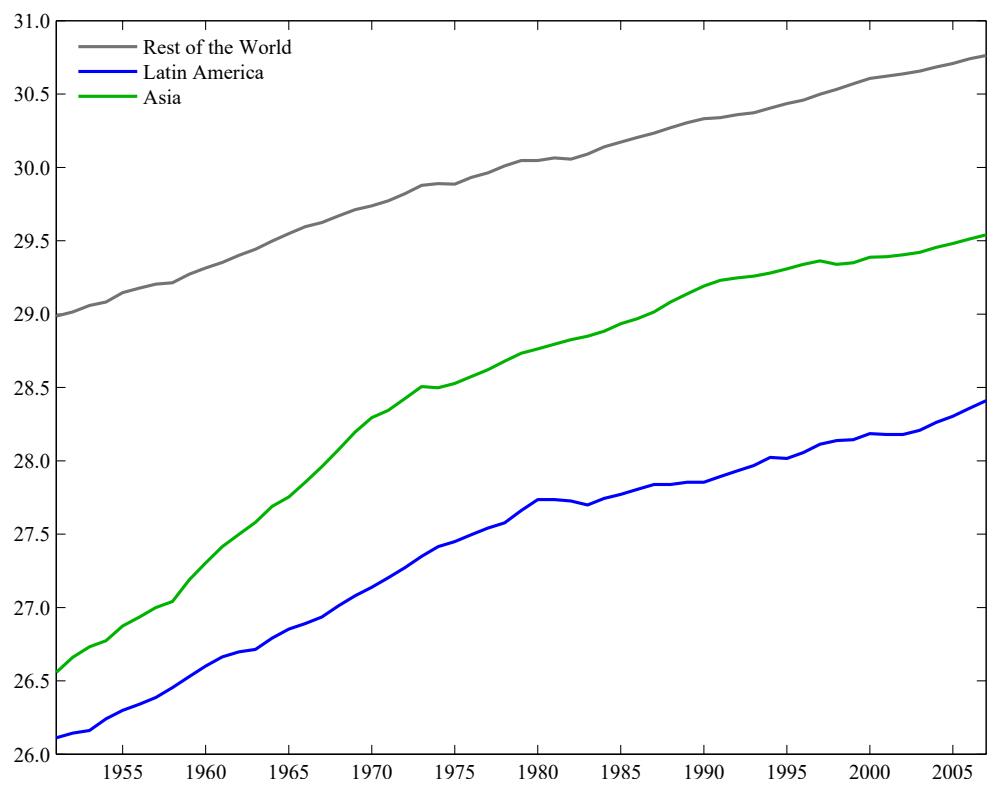

Figure 12: Consumption

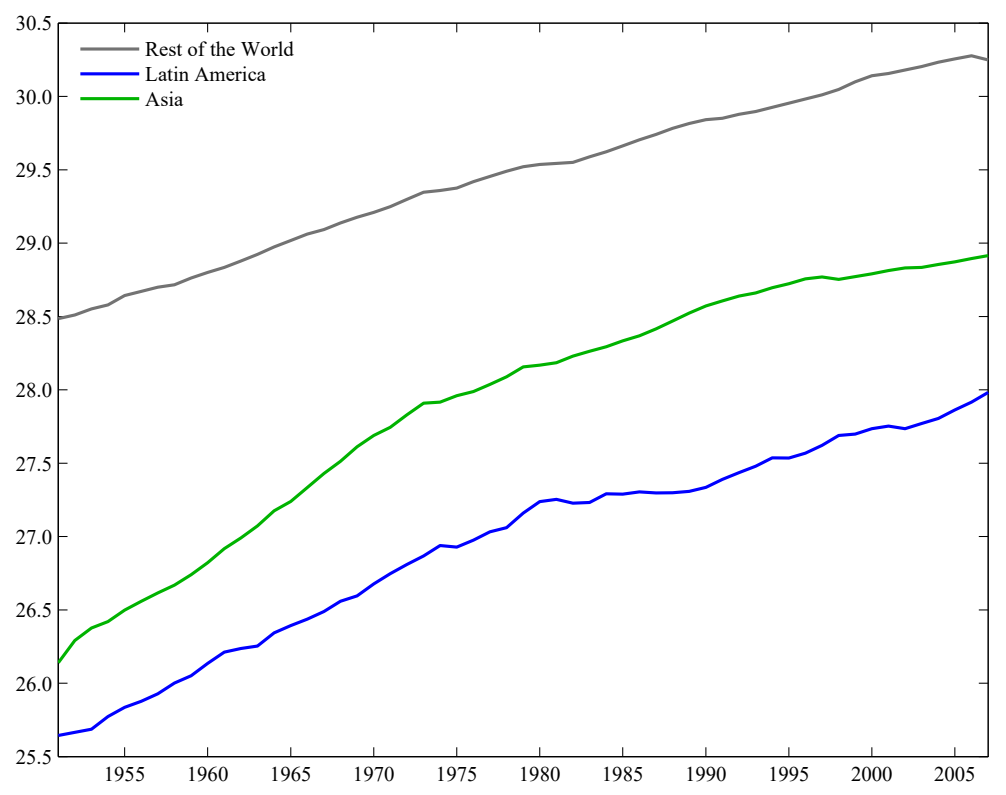


Figure 13: Investment

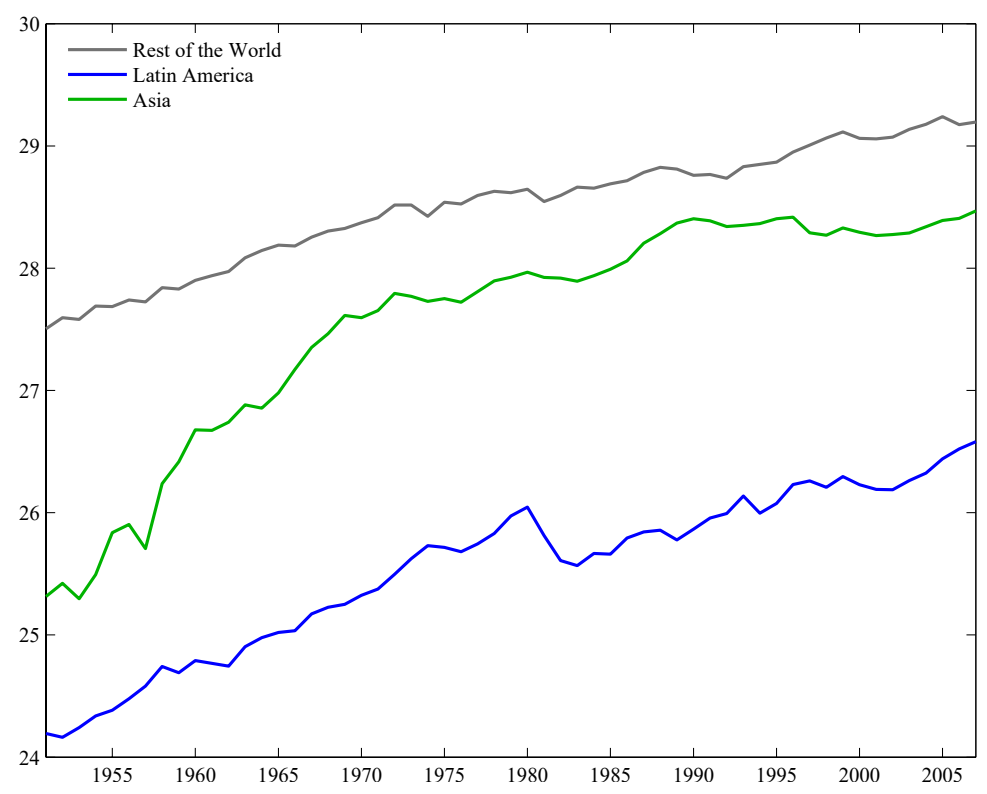

Figure 14: Per-capita Hours Worked

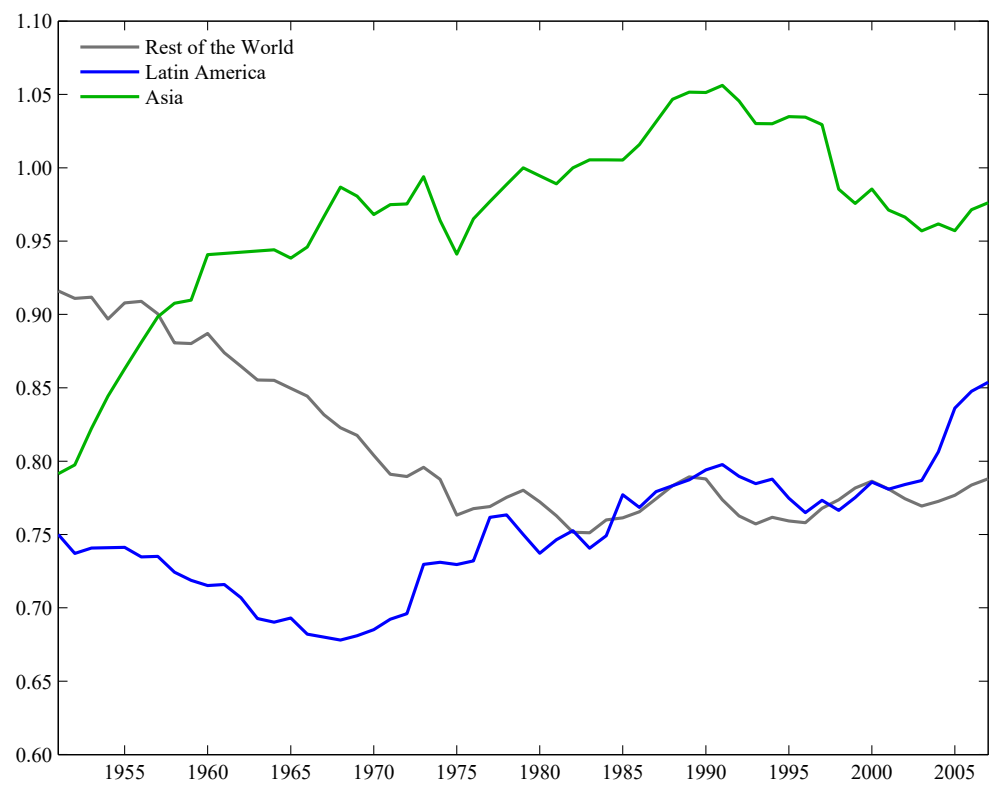


Figure 15: Population

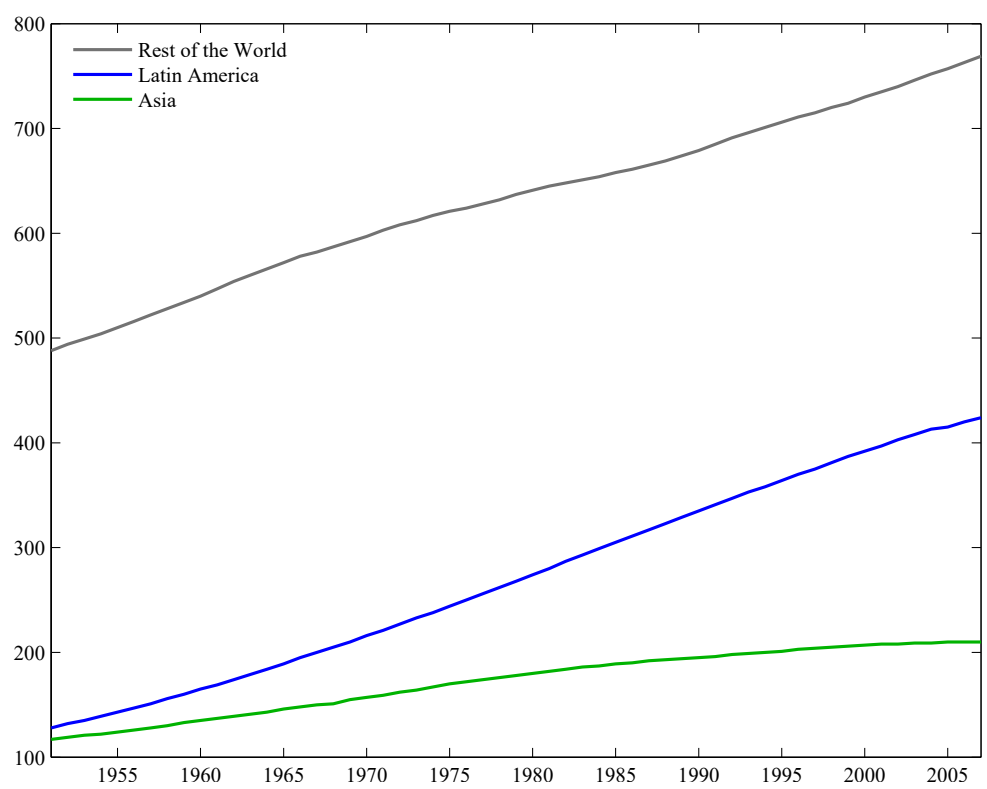

\section{Latin America}

- Mitchell, B. R. 2003. International historical statistics : the Americas, 1750-2000. New York: Palgrave Macmillan.

- Hofman, A. A. 2000. "Standardised capital stock estimates in Latin America: a 1950-94 update " Cambridge Journal of Economics, 24:1, pp. 45-86.

- The Economic Commission for Latin America and the Carribean's (ECLAC) Statistical Yearbook for Latin America and the Carribean.

- Della Paolera, Gerardo, Alan M. Taylor, and Carlos G. Bózzoli. 2003. "Historical Statistics," in A new economic history of Argentina. Gerardo Della Paolera and Alan M. Taylor eds. Cambridge ; New York: Cambridge University Press, pp. $376-85$.

- Taylor, Alan M. 2003. "Capital Accumulation," in A new economic history of Argentina. Gerardo Della Paolera and Alan M. Taylor eds. Cambridge ; New York: Cambridge University Press, pp. 170-96.

- Balboa, Manuel and Alberto Fracchia. 1959. "Fixed Reproducible Capital in Argentina, 1935-55." Review of Income and Wealth, 8, pp. 274-92. 
- Contador, Cláudio R. and Cláudio L. Haddad. 1975. "Produto Real, Moeda e Preços: A Experiência Brasileira no Período 1861-1970." Revista Brasileira de Estatística, 36:143, pp. 407-40.

- Patriota, Antãonio. 1961. The economic development of Brazil; a historical and quantitative study. [Stanford, Calif.: Hispanic American Studies, Stanford University.

- Joint Working Group of the Banco Nacional do Desenvolvimento Econãomico (Brazil) and the Economic Commission for Latin America. and Banco Nacional do Desenvolvimento Econãomico (Brazil). 1956. The economic development of Brazil. New York: United Nations Dept. of Economic and Social Affairs.

- Mamalakis, Markos. 1978. Historical statistics of Chile : national accounts. Westport, Conn.: Greenwood Press.

- Braun, Juan, Matías Braun, Ignacio Briones, José Díaz, Rolf Luders, and Gert Wagner. 2000. "Economía Chilena 1810-1995: Estadísticas Históricas." Universidad Católica de Chile Documento de Trabaj, 187.

\section{East Asia}

- Mitchell, B. R. 2003. International historical statistics : Africa, Asia E3 Oceania, 1750-2000. New York: Palgrave Macmillan.

- The Asian Development Bank's Key Indicators.

- Okawa, Kazushi, Miyohei Shinohara, and Larry Meissner. 1979. Patterns of Japanese economic development; a quantitative appraisal. New Haven: Yale University Press.

- Okawa, Kazushi and Henry Rosovsky. 1973. Japanese economic growth; trend acceleration in the twentieth century. Stanford, Calif.: Stanford University Press.

- Tsuru, Shigeto and Kazushi Ohkawa. 1953. "LONG-TERM CHANGES IN THE NATIONAL PRODUCT OF JAPAN SINCE 1878." Review of Income and Wealth, 3:1, pp. 19-44. 
- Yamada, Yuzo. 1955. "NOTES ON INCOME GROWTH AND THE RATE OF SAVING IN JAPAN A Brief Survey of Recent Estimates made by Research Workers at Hitosubashi University." Review of Income and Wealth, 5:1, pp. 22442 .

- United States Strategic Bombing Survey. 1946. The effects of strategic bombing on Japan's war economy. Washington, D. C.: Over-all Economic Effects Division.

- Cha, Myung Soo and Nak Nyeon Kim. 2006. "Korea's First Industrial Revolution, 1911-40." Naksungdae Institute of Economic Research Working Paper Series, 2006:3.

- Timmer, Marcel P. and Bart van Ark. 2002. "Capital Formation and Productivity Growth in South Korea and Taiwan: Beating Diminishing Returns through Realising the Catch-Up Potential." Groningen Growth and Development Centre Research Memorandum.

- Hwang, Insang and Kåonosuke Odaka. 2000. The long-term economic statistics of Korea : 1910-1990 : an international workshop. Tokyo: Institute of Economic Research, Hitotsubashi University.

- Pyo, Hak K. 1996. Historical Statistics of Korea: Investment and Capital Stock. Seoul: Institute of Economic Research, Seoul National University. (in Korean)

- Suh, Chang Chul. 1978. Growth and structural changes in the Korean economy, 1910-1940. Cambridge, Mass.: Council on East Asian Studies, Harvard University : distributed by Harvard University Press.

- Mizoguchi, Toshiyuki undated. "Estimate of Long-Term National Accounts Statistics of Taiwan: 1912-1990." Hiroshima University of Economics Working Paper.

\section{Appendix $\mathrm{C}$}

Figure 16 shows the prior and posterior distributions of the estimated parameters together with the posterior mode. 
Figure 16: Priors and Posteriors I
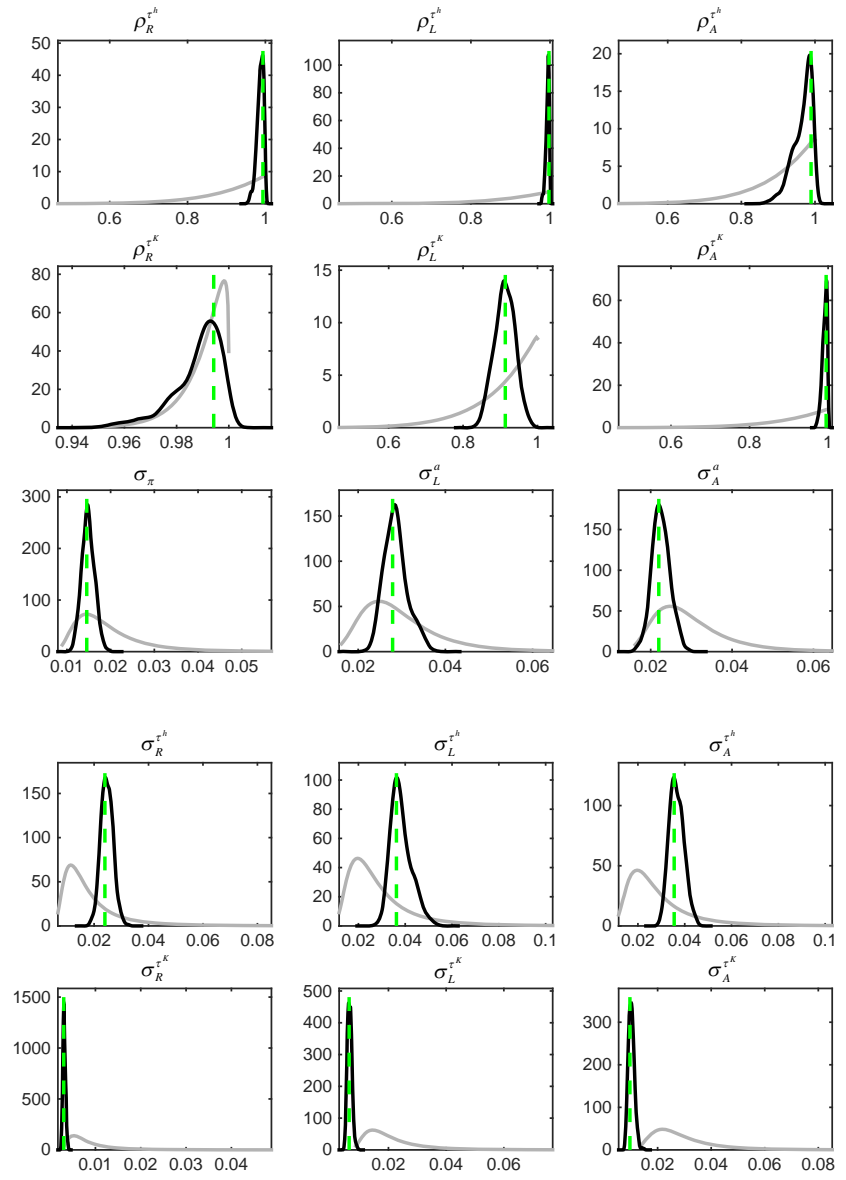

\section{Appendix D}

Figure 17 plots the government wedge identified from the data. 
Figure 17: The Government Wedge

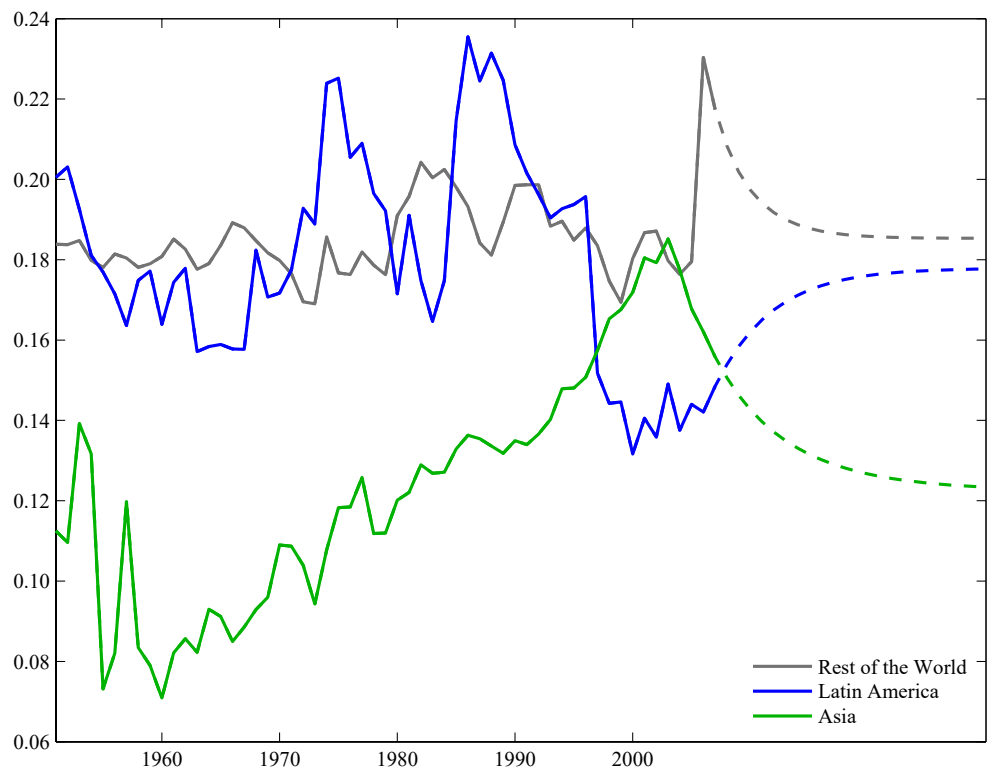

\section{Appendix E}

Tables 6 to 9 summarize the absolute relative contribution of the labor, capital and international wedges for consumption and output in each decade of our sample for both Asia and Latin America. Each number in each table is the decade average of the absolute marginal contribution of each wedge over the sum of the marginal contributions of all labor, capital and international wedges.

Table 6: Contribution of the different wedges for Latin American Consumption, by decade.

\begin{tabular}{|c|c|c|c|c|c|c|}
\hline Wedge Contributions & $1950 \mathrm{~s}$ & $1960 \mathrm{~s}$ & $1970 \mathrm{~s}$ & $1980 \mathrm{~s}$ & $1990 \mathrm{~s}$ & $2000 \mathrm{~s}$ \\
\hline \hline$\tau_{R}^{h}$ & 0.10 & 0.11 & 0.12 & 0.17 & 0.23 & 0.26 \\
\hline$\tau_{L}^{h}$ & 0.51 & 0.50 & 0.46 & 0.35 & 0.24 & 0.17 \\
\hline$\tau_{A}^{h}$ & 0.04 & 0.04 & 0.04 & 0.04 & 0.04 & 0.03 \\
\hline$\tau_{R}^{k}$ & 0.13 & 0.08 & 0.08 & 0.16 & 0.22 & 0.26 \\
\hline$\tau_{L}^{k}$ & 0.15 & 0.16 & 0.16 & 0.13 & 0.09 & 0.08 \\
\hline$\tau_{A}^{k}$ & 0.03 & 0.03 & 0.02 & 0.02 & 0.02 & 0.02 \\
\hline$\tau_{L}^{B}$ & 0.03 & 0.05 & 0.09 & 0.09 & 0.12 & 0.14 \\
\hline$\tau_{A}^{B}$ & 0.02 & 0.03 & 0.04 & 0.05 & 0.05 & 0.04 \\
\hline
\end{tabular}


Table 7: Contribution of the different wedges for Asian Consumption, by decade.

\begin{tabular}{|c|c|c|c|c|c|c|}
\hline Wedge Contributions & $1950 \mathrm{~s}$ & $1960 \mathrm{~s}$ & $1970 \mathrm{~s}$ & $1980 \mathrm{~s}$ & $1990 \mathrm{~s}$ & $2000 \mathrm{~s}$ \\
\hline \hline$\tau_{R}^{h}$ & 0.24 & 0.20 & 0.14 & 0.25 & 0.28 & 0.31 \\
\hline$\tau_{L}^{h}$ & 0.12 & 0.11 & 0.10 & 0.08 & 0.06 & 0.06 \\
\hline$\tau_{A}^{h}$ & 0.07 & 0.07 & 0.05 & 0.02 & 0.02 & 0.02 \\
\hline$\tau_{R}^{k}$ & 0.41 & 0.36 & 0.17 & 0.17 & 0.25 & 0.30 \\
\hline$\tau_{L}^{k}$ & 0.08 & 0.07 & 0.08 & 0.05 & 0.03 & 0.04 \\
\hline$\tau_{A}^{k}$ & 0.04 & 0.05 & 0.05 & 0.03 & 0.02 & 0.02 \\
\hline$\tau_{L}^{B}$ & 0.01 & 0.02 & 0.04 & 0.02 & 0.02 & 0.03 \\
\hline$\tau_{A}^{B}$ & 0.03 & 0.12 & 0.38 & 0.38 & 0.32 & 0.23 \\
\hline
\end{tabular}

Table 8: Contribution of the different wedges for Latin American Output, by decade.

\begin{tabular}{|c|c|c|c|c|c|c|}
\hline Wedge Contributions & $1950 \mathrm{~s}$ & $1960 \mathrm{~s}$ & $1970 \mathrm{~s}$ & $1980 \mathrm{~s}$ & $1990 \mathrm{~s}$ & $2000 \mathrm{~s}$ \\
\hline \hline$\tau_{R}^{h}$ & 0.15 & 0.08 & 0.06 & 0.07 & 0.06 & 0.06 \\
\hline$\tau_{L}^{h}$ & 0.28 & 0.50 & 0.53 & 0.51 & 0.49 & 0.47 \\
\hline$\tau_{A}^{h}$ & 0.06 & 0.03 & 0.02 & 0.02 & 0.02 & 0.01 \\
\hline$\tau_{R}^{k}$ & 0.16 & 0.07 & 0.06 & 0.07 & 0.08 & 0.08 \\
\hline$\tau_{L}^{k}$ & 0.22 & 0.24 & 0.26 & 0.27 & 0.29 & 0.31 \\
\hline$\tau_{A}^{k}$ & 0.05 & 0.02 & 0.01 & 0.01 & 0.01 & 0.01 \\
\hline$\tau_{L}^{B}$ & 0.04 & 0.03 & 0.03 & 0.03 & 0.03 & 0.03 \\
\hline$\tau_{A}^{B}$ & 0.04 & 0.02 & 0.02 & 0.02 & 0.02 & 0.01 \\
\hline
\end{tabular}

Table 9: Contribution of the different wedges for Asian Output, by decade.

\begin{tabular}{|c|c|c|c|c|c|c|}
\hline Wedge Contributions & $1950 \mathrm{~s}$ & $1960 \mathrm{~s}$ & $1970 \mathrm{~s}$ & $1980 \mathrm{~s}$ & $1990 \mathrm{~s}$ & $2000 \mathrm{~s}$ \\
\hline \hline$\tau_{R}^{h}$ & 0.22 & 0.15 & 0.23 & 0.24 & 0.23 & 0.27 \\
\hline$\tau_{L}^{h}$ & 0.12 & 0.10 & 0.08 & 0.07 & 0.06 & 0.06 \\
\hline$\tau_{A}^{h}$ & 0.18 & 0.29 & 0.17 & 0.20 & 0.21 & 0.15 \\
\hline$\tau_{R}^{k}$ & 0.30 & 0.21 & 0.25 & 0.24 & 0.23 & 0.26 \\
\hline$\tau_{L}^{k}$ & 0.08 & 0.07 & 0.04 & 0.03 & 0.03 & 0.04 \\
\hline$\tau_{A}^{k}$ & 0.06 & 0.07 & 0.10 & 0.12 & 0.14 & 0.16 \\
\hline$\tau_{L}^{B}$ & 0.02 & 0.02 & 0.01 & 0.01 & 0.01 & 0.01 \\
\hline$\tau_{A}^{B}$ & 0.04 & 0.10 & 0.12 & 0.09 & 0.08 & 0.06 \\
\hline
\end{tabular}

